\title{
THE USE OF SPHINGOMYELIN TO PROTECT AGAINST UV INDUCED DNA DAMAGE IN HUMAN KERATINOCYTES
}

\author{
A Thesis \\ presented to \\ the Faculty of California Polytechnic State University, \\ San Luis Obispo
}

\author{
In Partial Fulfillment \\ of the Requirements for the Degree \\ Master of Science in Biomedical Engineering
}

by

Kevin Campbell

June 2015 
(C) 2015

Kevin Campbell

ALL RIGHTS RESERVED 
TITLE:

AUTHOR:

DATE SUBMITTED:

COMMITTEE CHAIR:

COMMITTEE MEMBER:

COMMITTEE MEMBER:
The use of Sphingomyelin to protect against UV induced DNA damage in Human Keratinocytes

Kevin Campbell

June 2015

Lily Hsu Laiho, Ph.D.

Associate Professor of Biomedical Engineering

Rafael Jimenez-Flores, Ph.D.

Professor of Dairy Science

David Clague, Ph.D.

Associate Professor of Biomedical Engineering 


\begin{abstract}
The use of Sphingomyelin to protect against UV induced DNA damage in Human

Keratinocytes
\end{abstract}

Kevin Campbell

Non melanoma skin cancer (NMSC) is a serious condition caused by chronic ultraviolet (UV) exposure that leads to DNA damage in skin. UV radiation has the potential to lead to DNA damage, which triggers biochemical pathways within a cell. The result is that the cell either undergoes cell cycle arrest, giving the cell time to repair DNA damage, or apoptosis. Sunscreen is the most commonly used treatment for preventing UV induced skin damage, but it involves a number of undesirable and toxic side effects including damaging the dermis, premature aging of skin and underweight child births. This has led to interest in finding safer alternatives to prevent UV damage without the negative side effects of sunscreen. In particular, bovine milk sphingomyelin (SM) is a compound that has the potential to protect against UV damage without any of the dangerous side effects of sunscreen. Here we present the use of SM for UV protection of human keratinocytes (KRTs) to prevent DNA mutations that result from UV exposure. In particular, analysis of the expression of DNA damage biomarkers p21 and p53 was done to determine the potential of SM to prevent DNA damage associated with UV exposure. Both non-SM treated KRTs and KRTs treated with $0.1 \%$ SM media 24 hours prior to UV radiation were fixed and IF-stained at 24 hours following $40 \mathrm{~mJ} / \mathrm{cm}^{2}$ of UV exposure. Significant differences in both p21 and p53 were observed between the SM treated and non-SM treated cells at the UV dosage level (via t-test; $\mathrm{p}<0.05$ ). These findings suggest 
that $0.1 \%$ bovine SM treatment may impart photoprotective properties to KRTs and thus prevent UV associated DNA damage, which could potentially support further research into SM as a treatment to safely prevent the onset of non melanoma skin cancer.

Keywords: Keratinocytes, p21, p53, UV radiation, sphingomyelin, skin cancer 


\section{ACKNOWLEDGMENTS}

I would like to thank my thesis advisor, Dr. Lily Laiho, for all of her help through my thesis and graduate education. Your encouragement and patience have made this work possible, and have also inspired me to continue my graduate education in the form of a PhD. I appreciate all of your help through my time as a master's student and everything you have taught me about being a good scientist. I would also like to thank Dr. David Clague and Dr. Rafael Jimenez-Flores for being on my thesis committee and their support.

There are also a number of colleagues who I would like to thank for their help and time during this research. I would like to thank Kristina Bishard and Rebecca Kandell for all of the culturing work they did. I would also like to thank Leo Banuelos and Eric Robinson for all of their help staining, imaging and analyzing our data. Also, I would like to thank Justin Blonigan, Carl Miller, Gina Scott, Karissa Cardenas and Matt Feeley for their help and being such great labmates.

Last, I would like to thank my dad and the rest of my family for all of their support during this thesis process. My dad's motivation and the rest of my family's constant encouragement and have been important for the completion of my thesis, and I am grateful for their help. This help was essential for completing my thesis and degree, and I am lucky to have their support through this process. 


\section{TABLE OF CONTENTS}

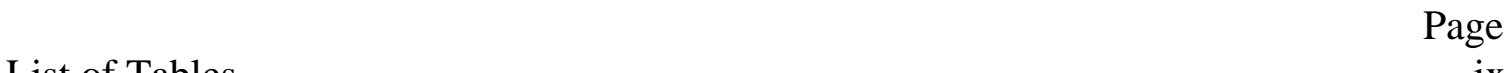

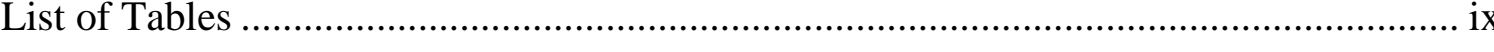

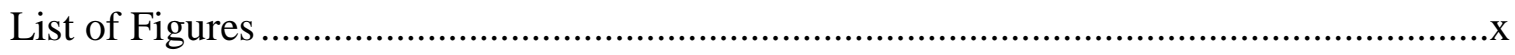

CHAPTER:

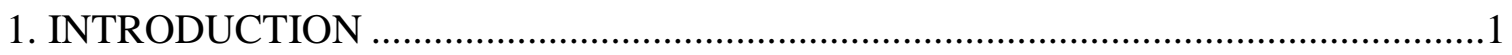

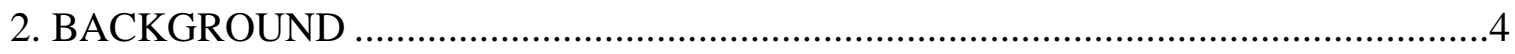

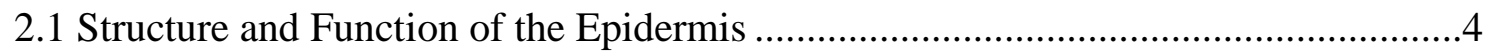

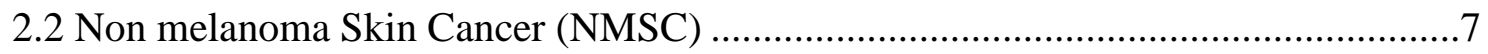

2.2.1 Types and Diagnoses ............................................................................

2.2.2 UV Radiation ………................................................................................

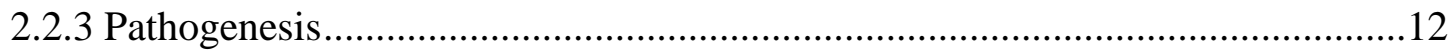

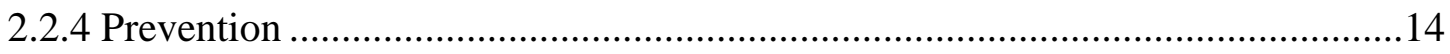

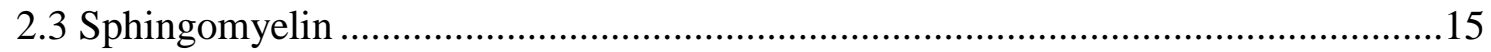

2.4 Human p21 Protein ........................................................................................19

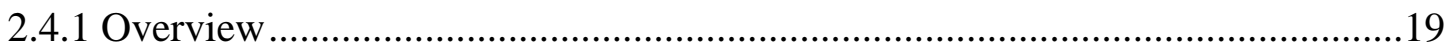

2.4.2 Interactions with Cyclin-CDKs...................................................................20

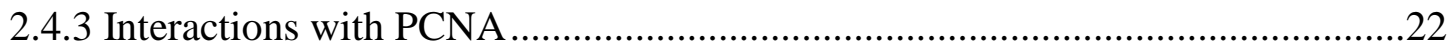

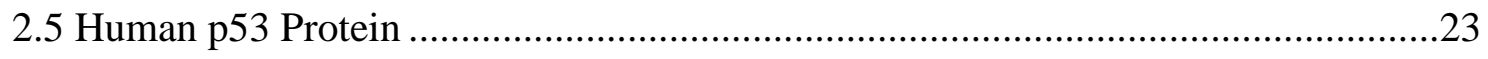

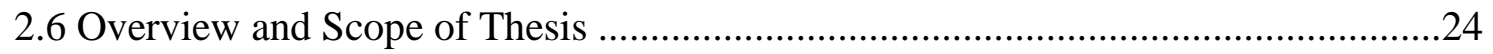

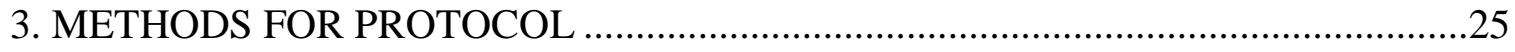

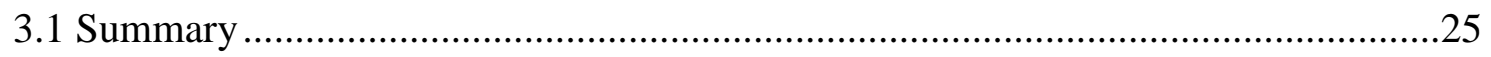

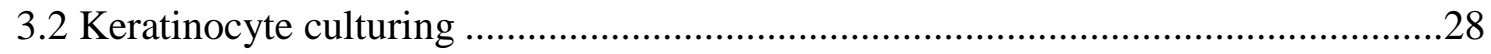

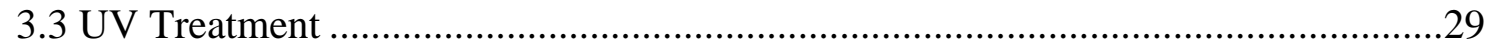

3.4 Fixation and Immunoflourescence Staining .........................................................

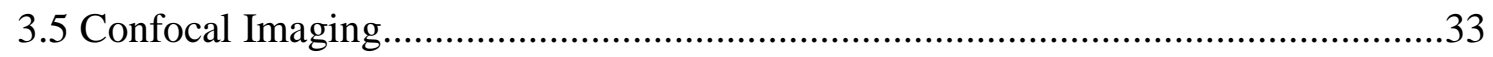

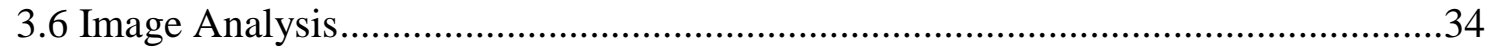

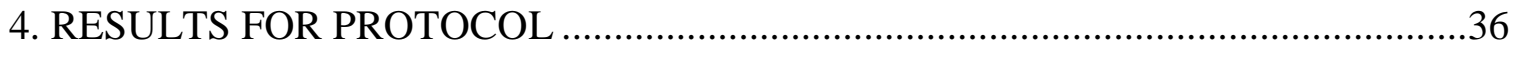

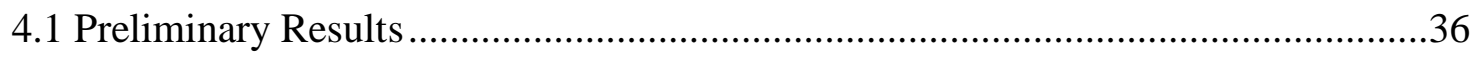

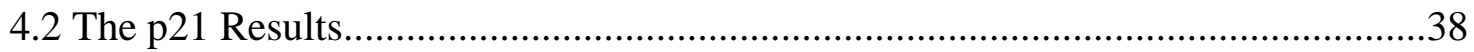

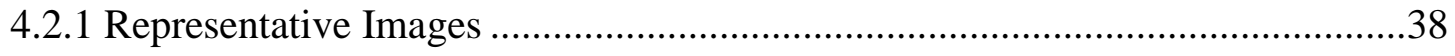




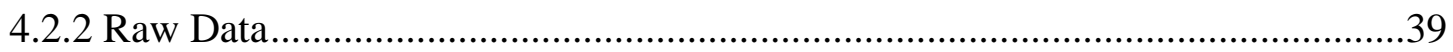

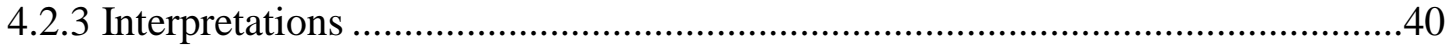

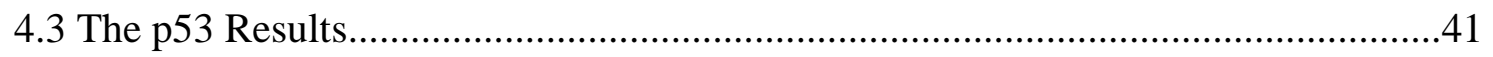

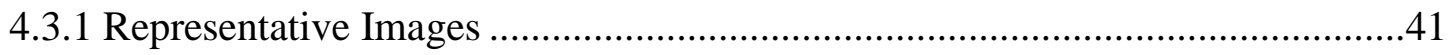

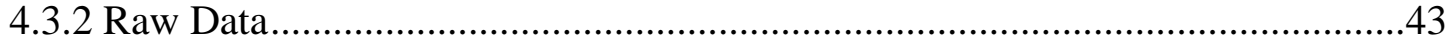

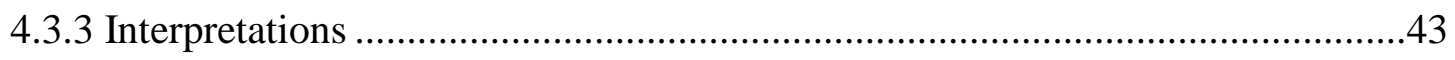

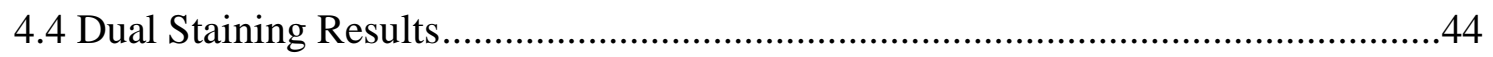

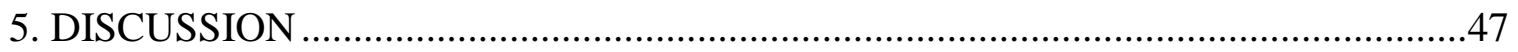

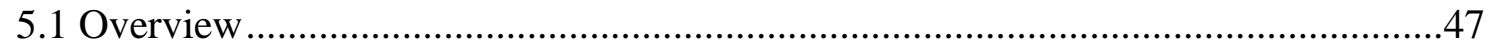

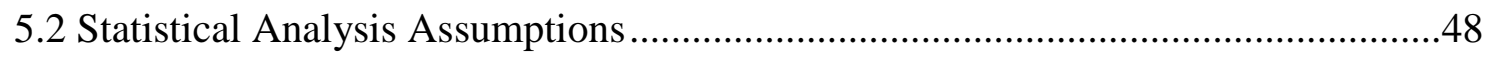

5.3 Observation of p21 and p53 as Biomarkers for DNA Damage ............................51

5.4 Theories on SM Mechanism for UV Protection ..................................................51

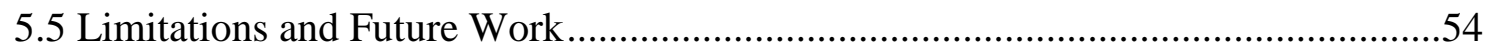

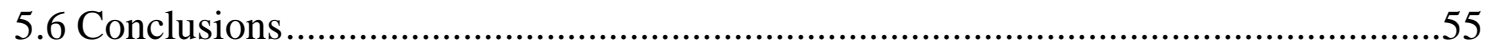

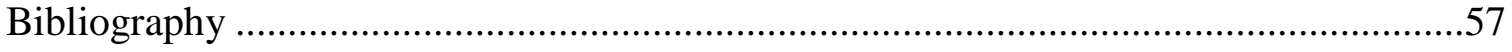




\section{LIST OF TABLES}

Page

Table 3.1 Summary of reagents and concentrations within these experiments ...............27

Table 3.2 List of Antibodies and Fluorescent Dyes used for each staining procedure.......33

Table 4.1 The ratio of $\mathrm{p} 21$ positive cells being expressed in each treatment group ..........40

Table 4.2 The ratio of 553 positive cells being expressed in each treatment group .........43 


\section{LIST OF FIGURES}

Figure 1.1 UV Induced DNA damage. UV radiation causes thymine and

pyrimidine dimer formation which leads to DNA damage repair 1

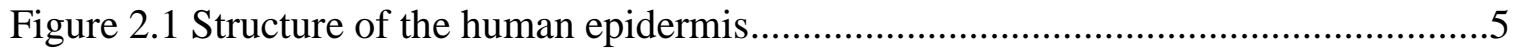

Figure 2.2 Clinical cases of BCC. (A) Rodent Ulcer. (B) Nodular. (C) Superficial.

(D) Morphoeic. (E) Pigmented .8

Figure 2.3 Clinical cases of precursor legions and SCC. (A) Actinic Keratosis. (B)

Bowen's Disease. (C) Keratoacanthoma. (D) SCC ….................................................

Figure 2.4 Different dimer formations resulting from UVB exposure ..........................11

Figure 2.5 Potential pathways to the development of NMSC …..................................13

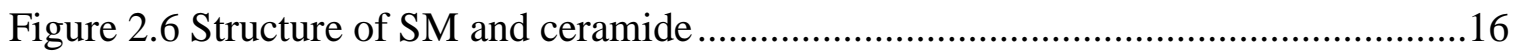

Figure 2.7 Mice colon without ceramide treatment (A,C), mice colon histology with

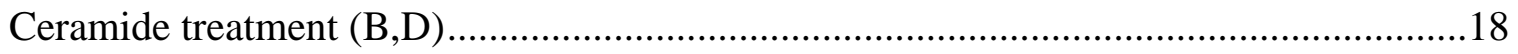

Figure 2.8 Example of a lipid raft microdomain......................................................19

Figure 2.9 Roles of CDK, RB and p21 (Cip) in cell cycle progression.........................21

Figure 3.1 Flowchart of the KRTs protocol for each treatment group ...........................26

Figure 3.2 Randomized group distribution for each plate. Yellow indicates UV .............29

Figure 3.3 UV box and lamp (top) and plate tray with and without cover (bottom).

The UV box, UV lamp and UV sensor were sterilized with IPA cleaning solution...........30

Figure 3.4 The Olympus FluoView FV1000 confocal microscope used for imaging.......34

Figure 4.1 Regions of poor confluency near the center of the well ................................36

Figure 4.2 Regions of poor signal to noise ratio attributed to insufficient blocking .........37

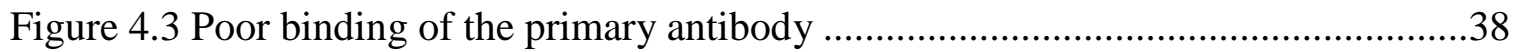

Figure 4.4 UV Treated Sphingomyelin Groups. No SM and no UV treatment (top row), No SM and UV treatment ( $2^{\text {nd }}$ row), $0.1 \%$ Sphingomyelin and no UV treatment $\left(3^{\text {rd }}\right.$ row), and $0.1 \%$ Sphingomyelin and UV treatment (last row). Regions in red are magnified KRTs showing p21 positive cells for UV treated KRTs and p21 negative cells for the no UV treated KRTs

Figure 4.5 UV Treated Sphingomyelin Results. The ratio of cells expressing nuclear p21 compared to the total number of cells in each group is plotted above. 
(*) $\mathrm{p}<0.05$; significant difference in ratio of cells expressing nuclear $\mathrm{p} 21$

Figure 4.6 UV Treated Sphingomyelin Groups. No SM and no UV treatment (top row), No SM and UV treatment ( $2^{\text {nd }}$ row), $0.1 \%$ Sphingomyelin and no UV treatment ( $3^{\text {rd }}$ row), and $0.1 \%$ Sphingomyelin and UV treatment (last row)

Figure 4.7 UV Treated Sphingomyelin Results. The ratio of cells expressing nuclear p53 compared to the total number of cells in each group is plotted above.

$\left(^{*}\right) \mathrm{p}<0.05$; significant difference in ratio of cells expressing nuclear $\mathrm{p} 53$

Figure 4.8 UV Treated Sphingomyelin Groups. No SM and no UV treatment (top row), No SM and UV treatment ( $2^{\text {nd }}$ row), $0.1 \%$ Sphingomyelin and no UV treatment $\left(3^{\text {rd }}\right.$ row), and $0.1 \%$ Sphingomyelin and UV treatment (last row).

Figure 5.1 Residuals of p21 positive cells. A) Probability plot of p21 responses.

B) Histogram of residuals of all treatment groups

Figure 5.2 Residuals of p53 positive cells. A) Probability plot of p53 responses.

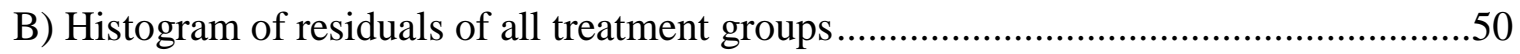

Figure 5.3 Role of sphingomyelin and ceramide in apoptosis 


\section{Chapter 1: Introduction}

Non melanoma skin cancer (NMSC) is the most prevalent form of cancer and is typically caused by ultraviolet (UV) radiation. In the United States alone, NMSC constitutes the largest percentage of new cancer cases with nearly 3.5 million new patients annually $[1,2]$. UV exposure leads to the formation of radical oxygen species, which are known to cause DNA damage, and the formation of thymine and pyrimidine dimers (See Figure 1.1) [3,4]. Following UV induced DNA damage, the cell will activate the DNA damage repair pathway [2]. Additional DNA damage increases the probability that DNA repair errors will occur resulting in mutations, potentially leading to the formation of NMSC [5].
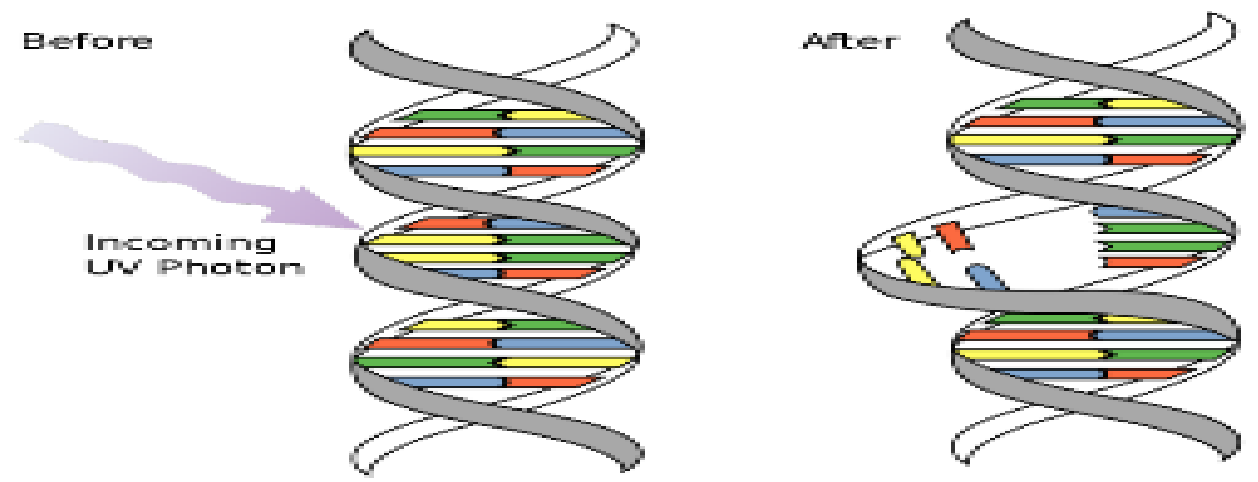

Figure 1.1 UV Induced DNA damage. UV radiation causes thymine and pyrimidine dimer formation which leads to DNA damage repair [3].

The two most common forms of skin cancer are basal and squamous cell carcinoma. Basal cell carcinoma constitutes nearly $80 \%$ of all NMSC cases and nearly two and a quarter million new diagnoses of basal skin cancer are expected in the US within the next year [6]. Squamous cell carcinoma is the next most common form of NMSC, afflicting nearly $20 \%$ of all skin cancer patients and this form is much more likely to metastasize than basal cell carcinoma [6]. The number of basal and squamous 
cell carcinoma cases are also increasing, with $350 \%$ more diagnosed patients observed annually between 1994 and 2006 [7]. The large increase in patients diagnosed with basal or squamous cancer now drives new research on how to safely prevent skin cancer.

One of the most common treatments available to prevent skin cancer formation is sunscreen. However, limitations of sunscreen include a number of toxic and undesirable side effects. Sunscreen includes heavy metal ions like zinc oxide and titanium nanoparticles that cause oxidative damage and can kill healthy cells $[3,8]$. Furthermore, pregnant women using sunscreens with oxybenzone are at risk of giving birth to underweight children [4]. These undesirable side effects have sparked interest at looking at alternatives to sunscreen. Previous work has shown that sphingomyelin (SM), a bovine milk phospholipid, has the potential to protect against UV damage without any of the toxic side effects associated with sunscreen [5]. Low concentrations of SM could potentially protect against UV damage by binding and dissolving lipid rafts in the plasma membrane thereby preventing the formation of radical oxygen species during UV exposure, which are carcinogenic and known to cause DNA damage $[2,6]$. The negative side effects associated with current treatments available to prevent skin cancer and the potential of SM has prompted interest in determining if SM can protect skin from UV damage.

Therefore, in this study we examine human keratinocytes (KRT) to determine if SM can prevent UV induced DNA damage. Specifically, the cyclin-dependent kinase inhibitor p21 and the tumor suppressor gene p53 has been shown to be up-regulated in response to DNA damage [7]. Nuclear expression of p53 occurs nearly immediately following UV induced DNA damage and increased expression of p53 has been linked to 
$\mathrm{G}_{2}$-phase arrest preventing the proliferation of potentially cancerous cells $[9,10,11]$. The nuclear expression of the cyclin kinase inhibitor p21 has also been shown to be increased in the presence of DNA damage and also leads to cell cycle arrest in cells expressing DNA damage, making the $\mathrm{p} 53$ and $\mathrm{p} 21$ proteins an ideal DNA damage biomarker to assess SM's effectiveness $[12,13]$. It is hypothesized SM treated KRTs will reduce DNA damage following UV exposure, which will lead to a decrease in the expression of $\mathrm{p} 21$ and p53 compared to KRTs without SM in the presence of UV. This study could potentially support further research into SM as a treatment to safely prevent the onset of NMSC. Here we studied p21 and p53 expression in KRTs exposed to UV radiation to determine the capacity of SM to protect against UV induced DNA damage and potential to prevent skin cancer. It is hypothesized that SM treated KRTs will reduce the expression of both $\mathrm{p} 21$ and $\mathrm{p} 53$ compared to KRTs without SM in the presence of UV, which could potentially support further research into SM as a treatment to safely prevent the onset of NMSC. 


\section{Chapter 2: Background:}

\subsection{Structure and Function of the Epidermis}

The integument, or skin, is the largest organ in the body, constituting about $7 \%$ of the total body weight and approaching $2 \mathrm{~m}^{2}$ of surface area in a typical adult [14]. Skin is composed from a stratified cellular epidermis surface layer, a dermis layer and a layer of subcutaneous fat separating striated muscle [14]. These layers provide a mechanical barrier against the outside world, preventing materials from entering or leaving the body. Skin also is responsible for realizing endogenous antibiotics to protect against microbials, production of melanin to prevent UV associated DNA damage, production of vitamin D along with other metabolic products and thermoregulation to control heat loss [14]. Each layer of skin has a unique composition and is responsible for specific functions to maintain homeostasis.

The outermost layer of skin is the epidermis layer and consists of keratinocytes which provide hydrodynamic regulation, innate immune response and melanin production [14]. The epidermis layer consists of multiple layers, including stratum corneum, granular layer, spinous layer, basal layer and a basement membrane (See Figure 2.1) [14]. The stratum corneum and granular layers are comprised of differentiated keratinocytes, which form a more flatten like structure due to the cytoskeleton being created from keratin intermediate filaments [14]. These differentiated keratinocytes within the stratum corneum are called corneocytes and have lost their nuclei and cytoplasmic organelles [14]. Corneocytes form a highly insoluble envelope within their plasma membranes by cross-linking soluble protein precursors and incorporation several lipids released from undifferentiated keratinocytes within lower layers of the epidermis 
[14]. This hydrophobic region of the stratum corneum helps control water loss or absorption through the skin [14]. The epidermis also consists of melanocytes and Langerhans' cells, which are responsible for producing melanin and antibiotics respectively [14]. Melanin plays an important role in preventing UV associated DNA damage and Langerhans' cells are antigen presenting cells which have a role in skin's adaptive immune response [14]. The dermis layer is below the epidermis and is connected via the basement membrane.

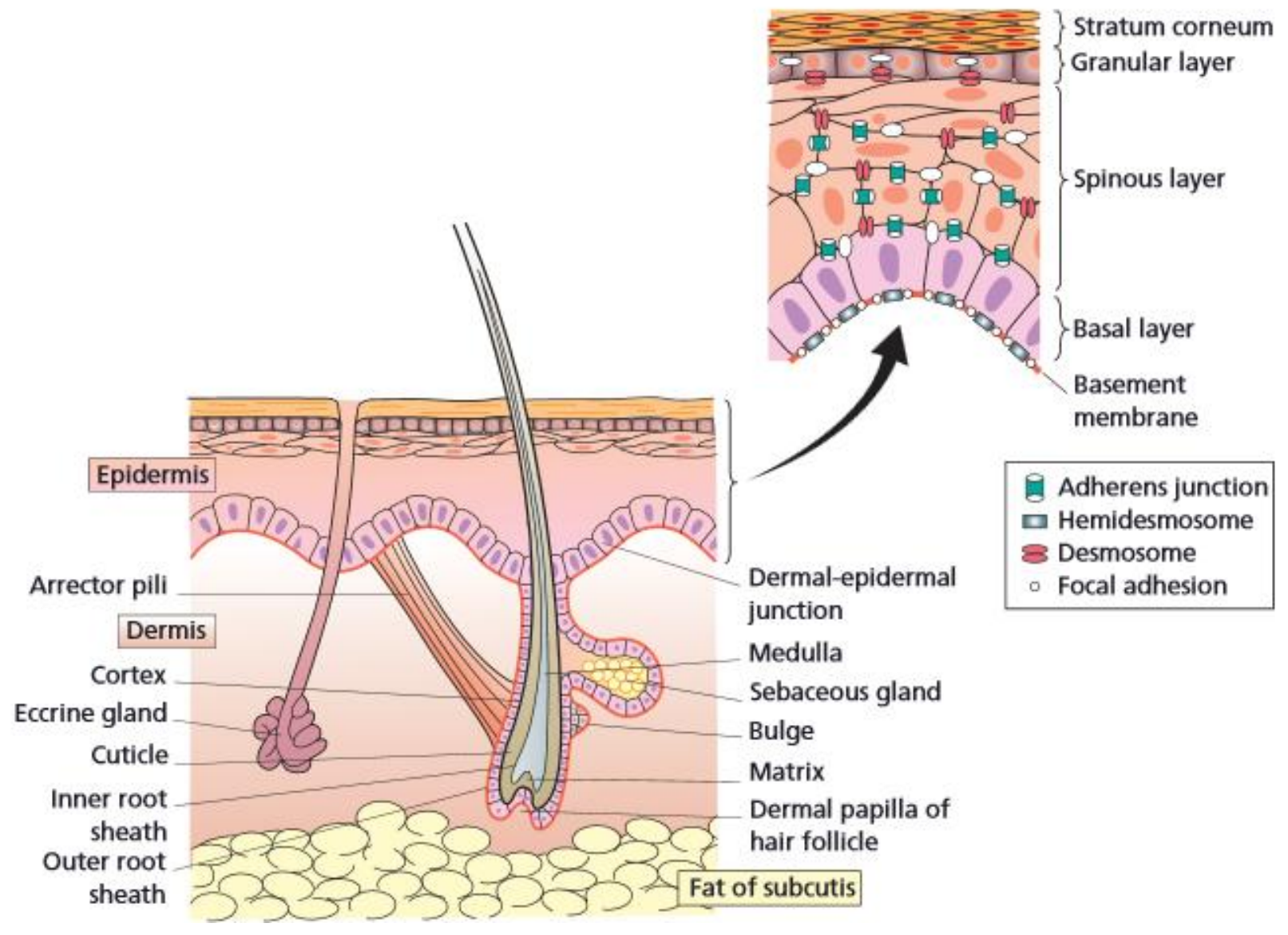

Figure 2.1 Structure of the human epidermis [14].

The dermis layer provides structural support for the skin and provides motor control, thermoregulation and additional hydration control [14]. The dermis is approximately 0.5 $\mathrm{mm}$ to $5 \mathrm{~mm}$ thick and is primarily composed of collagen and elastic tissue [14]. 
Approximately $80-85 \%$ of the weight of the dermis is attributed to collagen [14]. These collagen fibrils are extremely durable and provide skin with its tensile strength [14]. Elastic fibers account for about $2-4 \%$ of the extracellular matrix within the dermis and is responsible for the elasticity and resilience of skin [14]. Fibronectins, fibulins and integrins are responsible for cell adhesion and motility. The motor innervation is controlled automatically within the dermis and allows for control of the sweet glands and smooth muscles [14]. Blood vessels and the eccrine sweat glands occupy the dermis, which allows for thermoregulation through perspiration and vasodilation/constriction [14]. The region between both the collagen and elastic tissue is occupied by glycosaminoglycan and proteoglycan macromolecules, which are very hydrophilic and provide high regions of water affinity. This helps maintain water within the dermis, providing additional hydrodynamic regulation.

Subcutaneous fat is beneath the dermis and provides support as well energy reserves and hormone regulation [14]. Nearly $80 \%$ of the total body fat is found in subcutaneous tissue in non-obese individuals. This subcutaneous fat provides support against trauma related injuries and provides a significant deposit of calorie reserve. In addition to preventing injury and energy storage, the subcutaneous fat beneath the dermis also has an endocrine function including the release of leptin, which regulates hunger and energy metabolism [14]. 


\subsection{Non Melanoma Skin Cancer (NMSC)}

\subsubsection{Types and Diagnoses}

NMSC is a serious condition and includes cutaneous lymphomas, Merkel-cell carcinoma and adnexal tumors, though basal-cell carcinomas (BCC) and squamous-cell carcinomas (SCC) are the primary forms of NMSC [15]. NMSC is the most prevalent skin cancer and there are over two million new cases of NMSC each year in the United States alone. BCC is the most common form of NMSC, constituting about $70-80 \%$ of new NMSC cases [15]. SCC cases are less prevalent than BCC, constituting nearly 20$30 \%$ of total NMSC cases, though SCC is much more likely to metastasize than BCC [15]. The number of NMSC have been steadily increasing since 1960 worldwide, with an average 3-8\% increase in incidents per year [15].

BCC usually appear as small and translucent discolorations on the skin of patients [15]. The head and neck are the most common regions of BCC formation, constituting nearly $80 \%$ of all BCC cases. Clinical diagnosis is typically straightforward for the head and neck region and involves a skin biopsy. Formation of superficial BCC on the trunk of patients is rarer, but has been shown be both increasing and harder to diagnosis due to difficulty defining boarders of the carcinoma and distinguishing $\mathrm{BCC}$ from other possible disease [15]. The more common types of BCC include rodent ulcers, nodular, superficial, morphoeic and pigmented carcinoma (See Figure 2.2) [15]. 

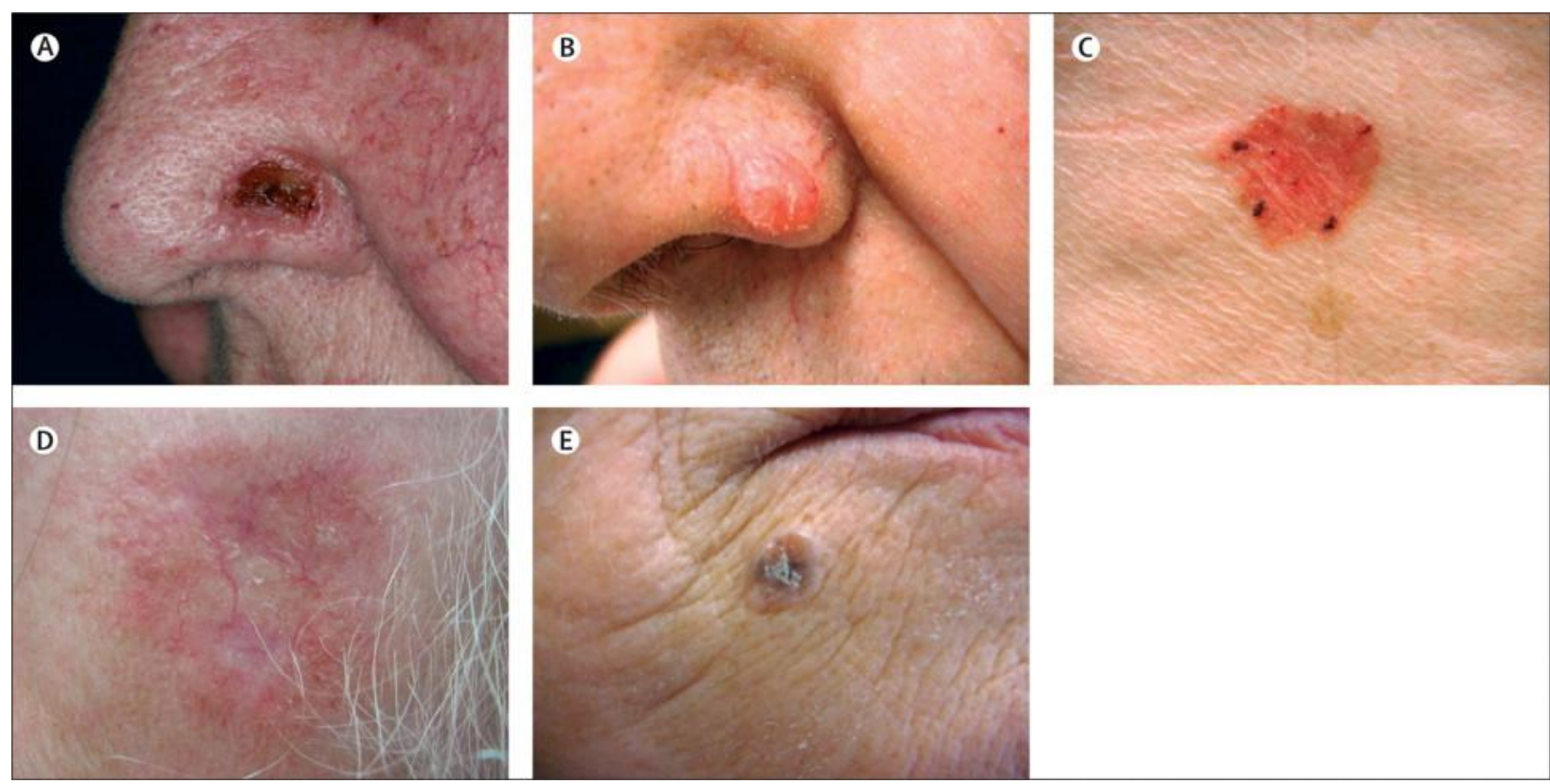

Figure 2.2 Clinical cases of BCC. (A) Rodent Ulcer. (B) Nodular. (C) Superficial. (D) Morphoeic. (E) Pigmented [15].

SCC are more likely to be malignant and can have precursor legions including actinic keratoses and Bowen's disease [15]. Actinic keratosis are legions that can indicate high UV exposure and an increased risk of being diagnosed with SCC (See Figure 2.3) [15]. Although the formation of invasive SCC from single actinic keratoses is approximately $1-10 \%$ over the course of 10 years, the risk of forming SCC increases with more actinic keratosis [15]. Lesions from Bowen's disease usually are present in regions of sun exposed areas and are slowly enlarging crusted plaques (See Figure 2.3) [15]. These legions are typically hard to define and have a 3-5\% chance of progressing to SCC [15]. Histopathological examination is the most common method of diagnosing NMSC, but non-invasive screening including dermoscopy, ultrasound, optical coherence tomography and in-vivo confocal microscopy have had success diagnosing NMSC [15]. 

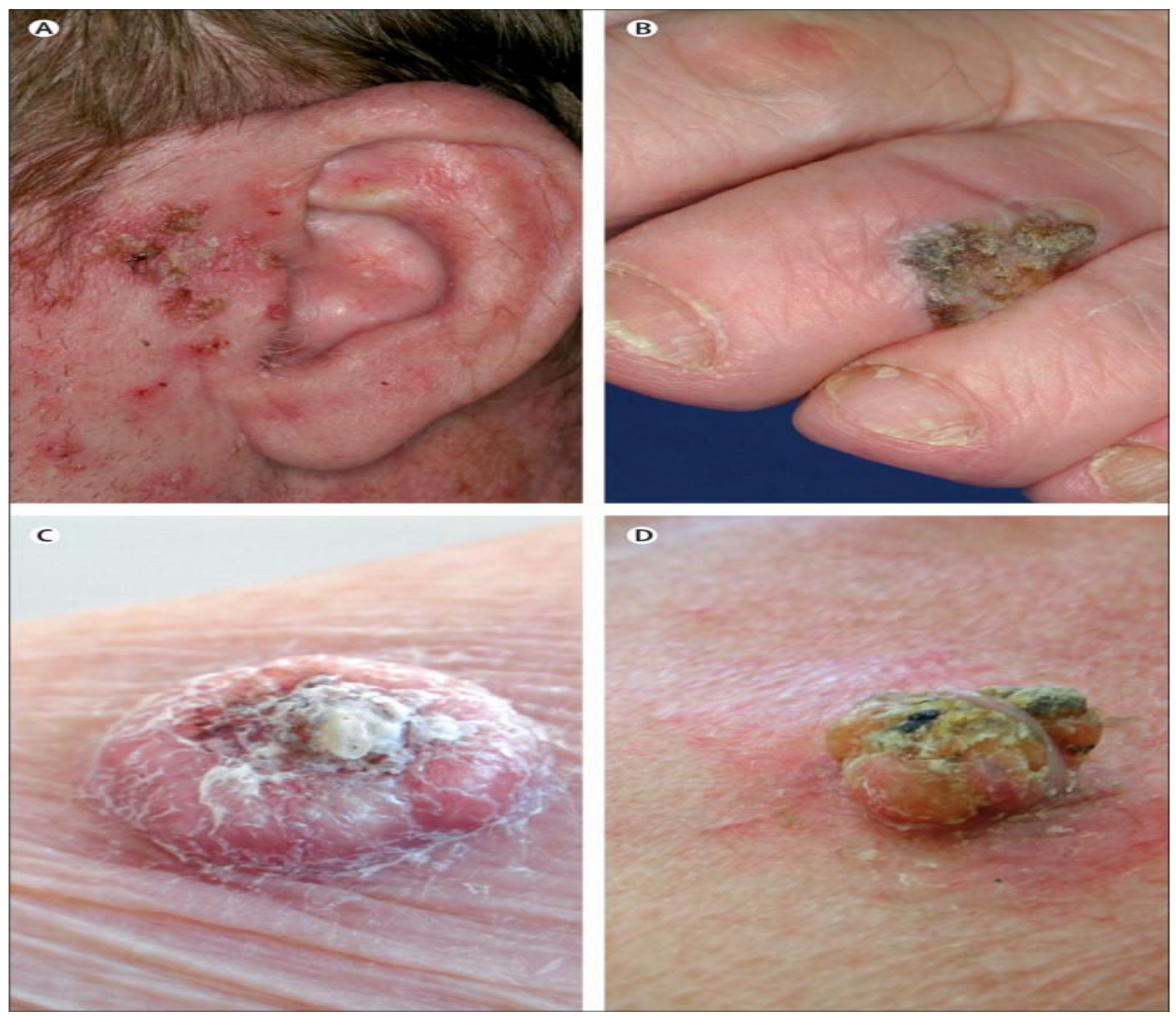

Figure 2.3 Clinical cases of precursor legions and SCC. (A) Actinic Keratosis. (B) Bowen's Disease. (C) Keratoacanthoma. (D) SCC. [15]

\subsubsection{UV Radiation}

Exposure to the sun's radiation is the primary cause of NMSC [16]. The solar spectrum consists of UV radiation, visible light and infrared, with UV only accounting for $5 \%$ of the total sunlight reaching earth [16]. UV radiation is split into UVA (320nm400nm), UVB (290nm-320nm) and UVC (100nm-290nm). Although the position of the sun above the horizon, the time of day, day of the year and geographical location affects UV exposure, typically UVA constitutes $94 \%$ of total terrestrial UV and UVB constitutes 
$6 \%$ [16]. Radical oxygen species, reactive nitrogen species and reactive sulfur species in the upper atmosphere are responsible for absorbing all UVC radiation, which is the most potent DNA damaging UV region, and most of the UVB region [16]. Even though UVA is the most abundant terrestrial UV, UVB is much more likely to lead to DNA damage [16]. As a result, UVB has been liked to causing nearly $80 \%$ of NMSC and is used in the course of this study to induce DNA damage [16].

UVB radiation has been linked to causing DNA damage and NMSC. UV radiation has been found to cause cyclobutane pyrimidine dimers from adjacent pyrimidine bases in DNA strands [17]. In addition, another dimer at the di-pyrimidine site, the 6-4 photoproduct, has been identified as a product of UVB radiation [17]. These dimers are removed and repaired with a process called nucleotide excision repair, though higher frequency of these dimers has been linked to DNA mutations (See Figure 2.4) [17]. Frequent exposure to UVB radiation has also been associated with mutations with the TP53 tumor gene, which is responsible for the transcription of p53 and later downstream cell cycle arrest activating proteins [17]. Mutations with the TP53 tumor gene and consequently the p53 protein impedes the cells ability to repair DNA damage, increasing the risk of forming NMSC [17]. 


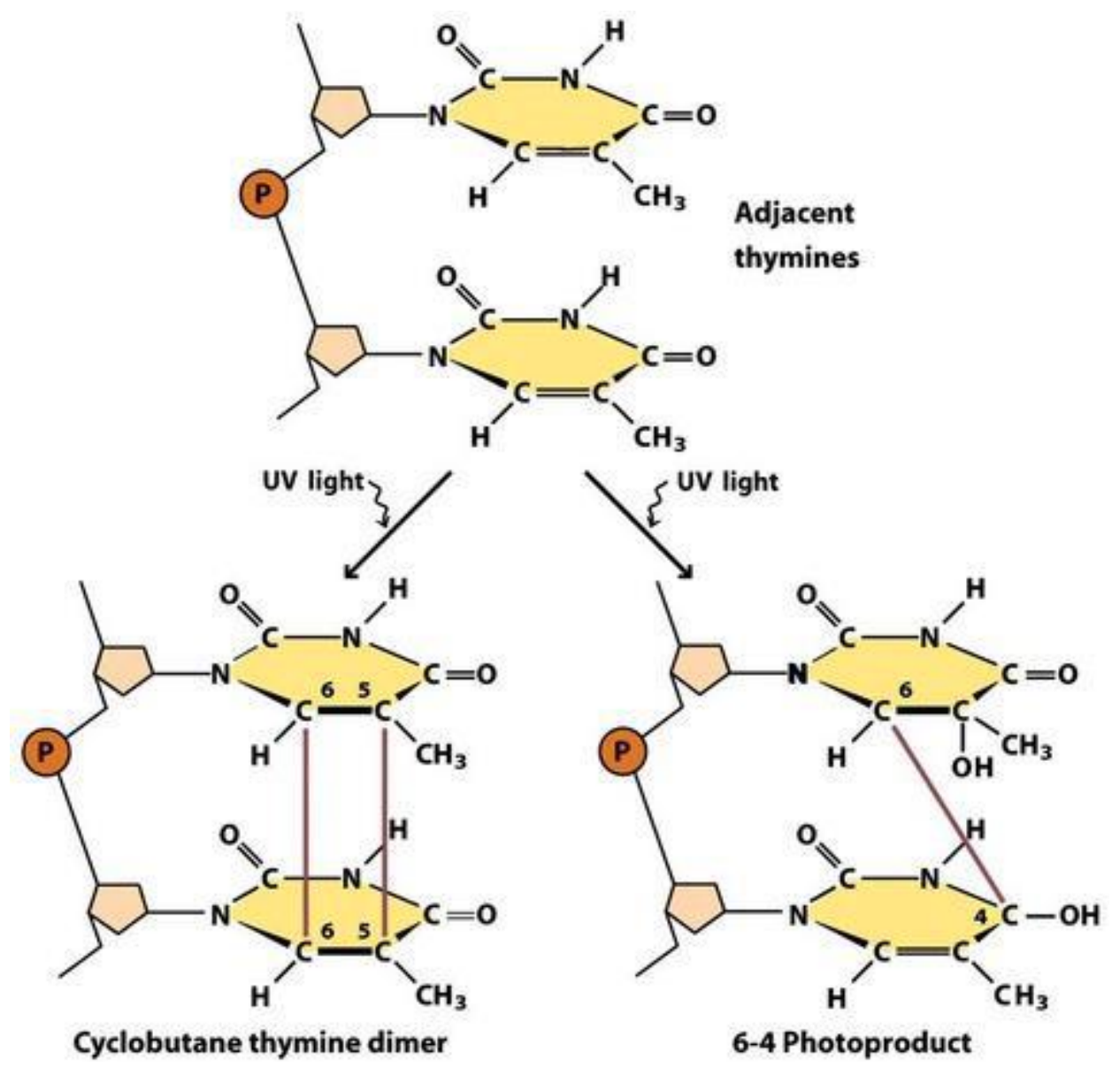

Figure 2.4 Different dimer formations resulting from UVB exposure [18].

Although UVB causes the majority of DNA damage, UVA has also been associated to indirectly cause DNA damage. The thiopurine 6-mercaptopurine absorbs in the UVA region and forms radical oxygen species [19]. Radical oxygen species have well understood mechanism of causing DNA damage, and abrupt increases in these reactive species can lead to oxidative stress and mutagenic DNA legions [19]. The cell does have pathways to neutralize radical oxygen species, but rapid changes in these radical species can cause DNA damage prior to neutralization [19]. UV radiation is a potent cause of NMSC through the DNA damage caused directly by UVB and indirectly through the formation of radical oxygen species with UVA exposure. 


\subsubsection{Pathogenesis}

Extensive exposure to the sun's radiation is linked to causing NMSC [20]. In particular, UV radiation from the sun could cause NMSC by causing mutations in the DNA, inducing immune-suppression that might inhibit tumor prevention and could also lead to persistent infection with Human Papilloma Viruses [20]. Figure 2.5 shows how UV exposure can increase the risk of forming NMSC by damaging DNA and activating cell cycle arrest/DNA repair and weakening the immune system against subsequent infections [20]. Aging was also found to decrease the capacity to repair DNA damage [20]. Although the mechanism for the suppression of the immune response is not clearly understood, there is strong evidence linking the reduction of the immune response with prolonged UV exposure [20]. In addition, the risk for forming NMSC increases with age, as the immune system and capacity to repair DNA decreases with older patients [20]. 


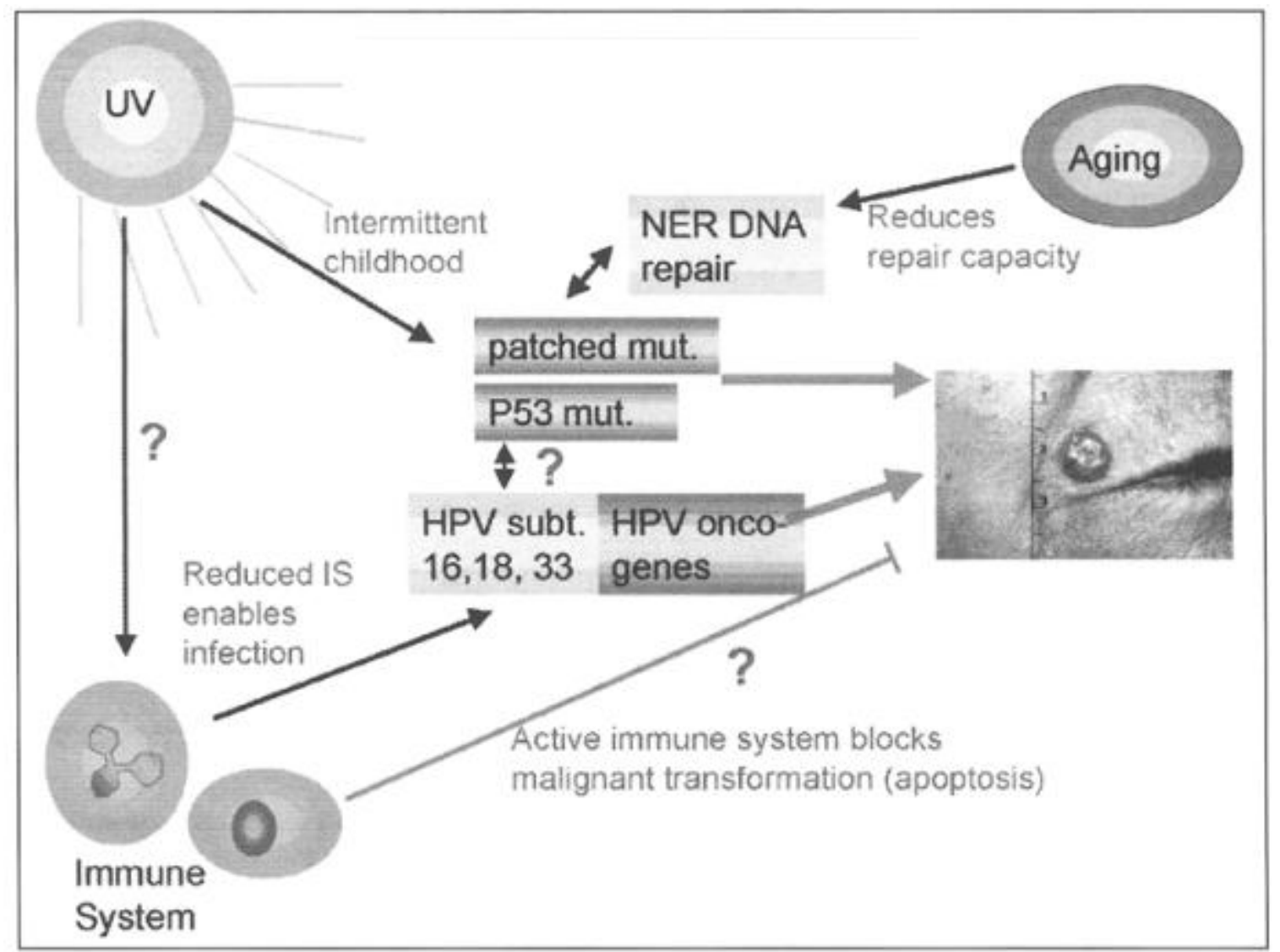

Figure 2.5 Potential pathways to the development of NMSC [20]

Mutations in specific regions of the genome increase the risk of NMSC. Over half of the cases of BCC have been linked with mutations in the Hedgehog pathway related genes, especially PTCH1, in animal models [4]. Mutations in the p53 tumor suppressor gene are extremely common in animals with precancerous lesions and SCC [4]. These mutations have not only been linked to carcinogenesis, but also mutagenesis and premature aging [4]. Direct DNA damage is repaired with nucleotide excision repair pathway and DNA damage from radical oxygen species are repaired via base excision repair [4]. However, mutations in the regulatory genes and a reduction of the immune response increases the likelihood of NMSC formation [4]. 


\subsubsection{Prevention}

There a currently numerous methods for preventing the onset of NMSC. Some of these methods include avoiding sun exposure between 10 am to $4 \mathrm{pm}$, wearing sunprotective clothing, using sunscreen with a sun-protection factor greater than 15 and avoiding artificial sources of UV [21]. Sunscreen is one of the most common treatments available to prevent NMSC, and has been shown to inhibit the transmission of UV by absorbing, scattering or reflecting UV radiation depending on the present active ingredients [22]. Sunscreens typically contain either organic or inorganic active ingredients. Organic sunscreens are usually derivates of salicylates, p-aminobenzoates, dibenzoylmethanes, cinnamates, camphors, benzophenones or anthranilates [22]. These organic components will absorb the higher energy UV and will undergo a chemical reaction releasing heat [22]. Inorganic sunscreens typically include microfine particles of titanium dioxide and zinc oxide coated with silicone, fatty acids or oxides of aluminum, silicon or zirconium [22]. These particles are designed to scatter and reflect UV radiation to prevent UV radiation from reaching skin. Sunscreen has been shown to be effective against preventing UVB exposure proportionally to the sun-protection factor. Rodent models have shown that sunscreen reduces local immunosuppression, p53 mutations and the formation of actinic keratosis, thereby reducing the likelihood of NMSC formation $[22]$.

A number of toxic and undesirable side effects limit the application of sunscreen. A number of active components found in organic sunscreens including $p$-Aminobenzoic acid, benzophenone-9 and 2-phenylbenzimidazole-5-sulfonic acid which were found to be potentially carcinogenic [22]. When tested with in vitro cytotoxicity studies they were 
found to induce cyclobutane dimers in mammalian DNA and adducts with thymine and thymidine following UV exposure [23]. In addition, components like oxybenzone are commonly used in sunscreens and is listed as very hazardous by the center for disease control and prevention [24]. Oxybenzone is also on the registry of toxic effects of chemical substances because of the chemicals capacity to absorb through the skin and disrupt endocrine function [24]. Mothers with high oxybenzone blood levels are at risk of giving birth to underweight children and extended exposure to oxybenzone can also lead to the formation of photocontact allergic reactions [25]. Titanium nanoparticles and zinc oxide are also commonly used in sunscreens to reflect UV radiation and have also been noted to have cytotoxicity and genotoxicity properties [8]. These toxic side effects associated with sunscreen usage has prompted interest in finding safer alternatives to prevent skin cancer.

\subsection{Sphingomyelin}

Bovine milk sphingomyelin (SM) is a phospholipid found in bovine milk which is believed to have anticarcinogenic properties. Phospholipids make up a small percentage $(<1 \%)$ of all the lipids found in milk, with SM constituting approximately $18-20 \%$ of the total phospholipid concentration [26]. SM is also found naturally within the outer leaflet of the plasma membrane of cells. When triacylgyerols, including sphingomyelin, are exposed to other cell membranes, they are incorporated into the fat globule membrane of the cell [26]. Approximately $10 \%$ of all digested sphingomyelin is believed to escape digestion and is transported throughout the body [27]. The addition of sphingomyelin to the plasma membrane has been linked to having anticarcinogenic effects. In particular, the use of sphingomyelin has been linked to acting as inhibitors of colon carcinogenesis. 
In the case of colon cancer, the incorporation of sphingomyelin within the colon was found to reduce colon cancer incidents without any evidence of toxic side effects [28]. Interest in determining if sphingomyelin is effective against other types of cancers have lead to further carcinogenic studies with sphingomyelin. Previous in vitro studies have found trends that support sphingomyelin protecting keratinocytes from UV induced DNA damage, which could have applications in protecting against skin cancer [28].

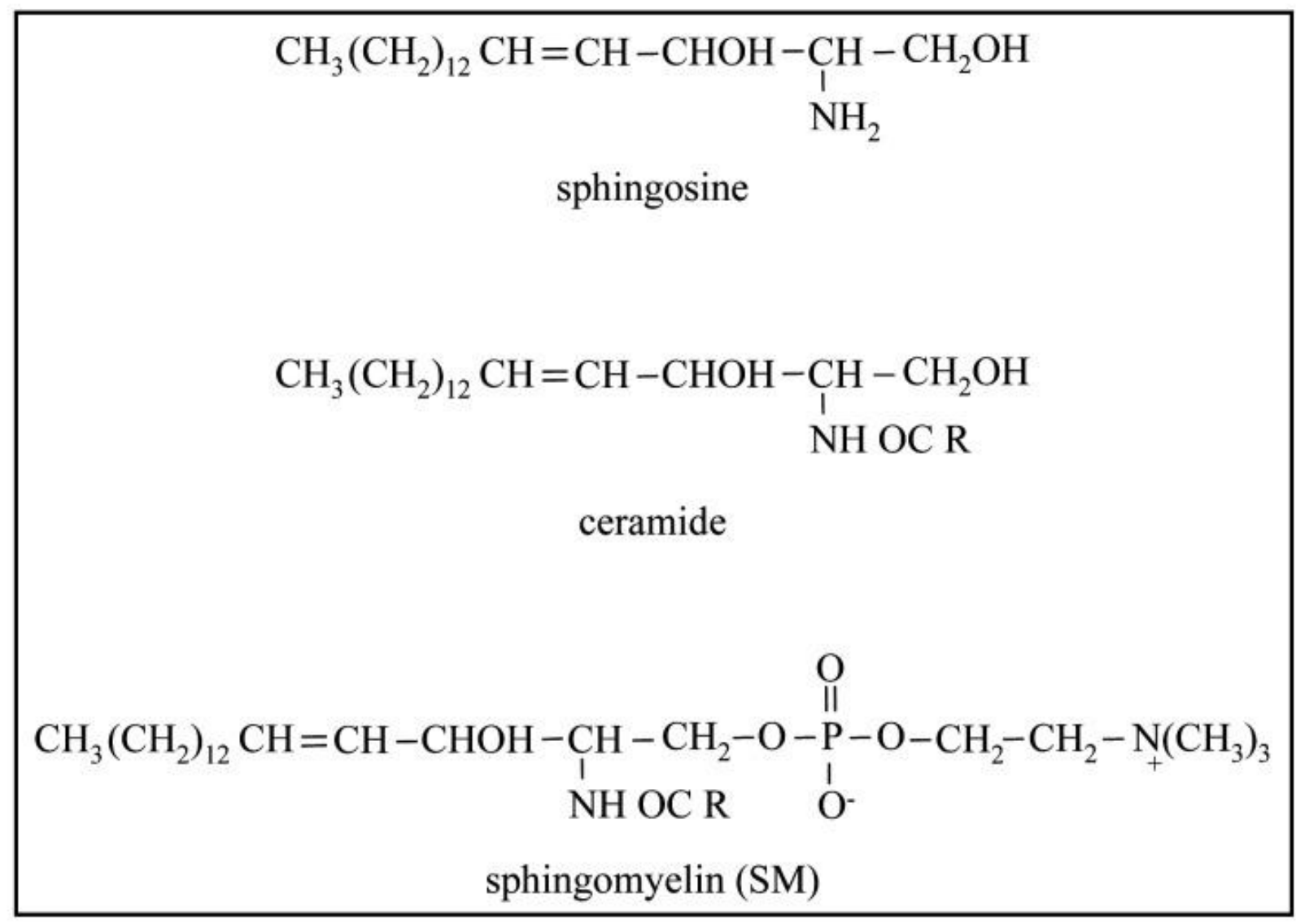

Figure 2.6 Structure of SM and ceramide [29].

SM is a polar lipid which constitutes a major component of plasma membranes and could have pathways to prevent cancer formation. SM contains a phosphorylcholine polar head group, a sphingosine backbone and a short region of paraffinic residues [30]. This region of paraffinic residues contain an acyl chain that is typically long and is either 
saturated or contain many cis double bonds [30]. The structure of SM is composed of ceramide, which is a bioactive lipid that is in equilibrium with the synthesis and hydrolysis of SM (See figure 2.6) [30]. Ceramide has been shown to have important roles in growth arrest, differentiation and apoptosis in many different cell types [30]. In particular, human colon cancers have observed significant decreases in the amount of available ceramide [30]. Restoration of ceramide in mice transfected with human colon cancer found tumor free livers in the mice, while mice with ceramide deficiencies were found to develop liver tumors (See figure 2.7) [30]. Increases in the ceramide levels were believed to induce apoptosis in cancerous cells, making a ceramide a potential anti-cancer therapy. Increases in SM have been linked to increasing ceramide, which could provide a mechanism for how SM could impart protection against cancer formation. KRTs were found to have a significant increase in ceramide levels after being treated with SM, which has prompted further interest in investigating the role SM might have in preventing skin cancer [31]. 

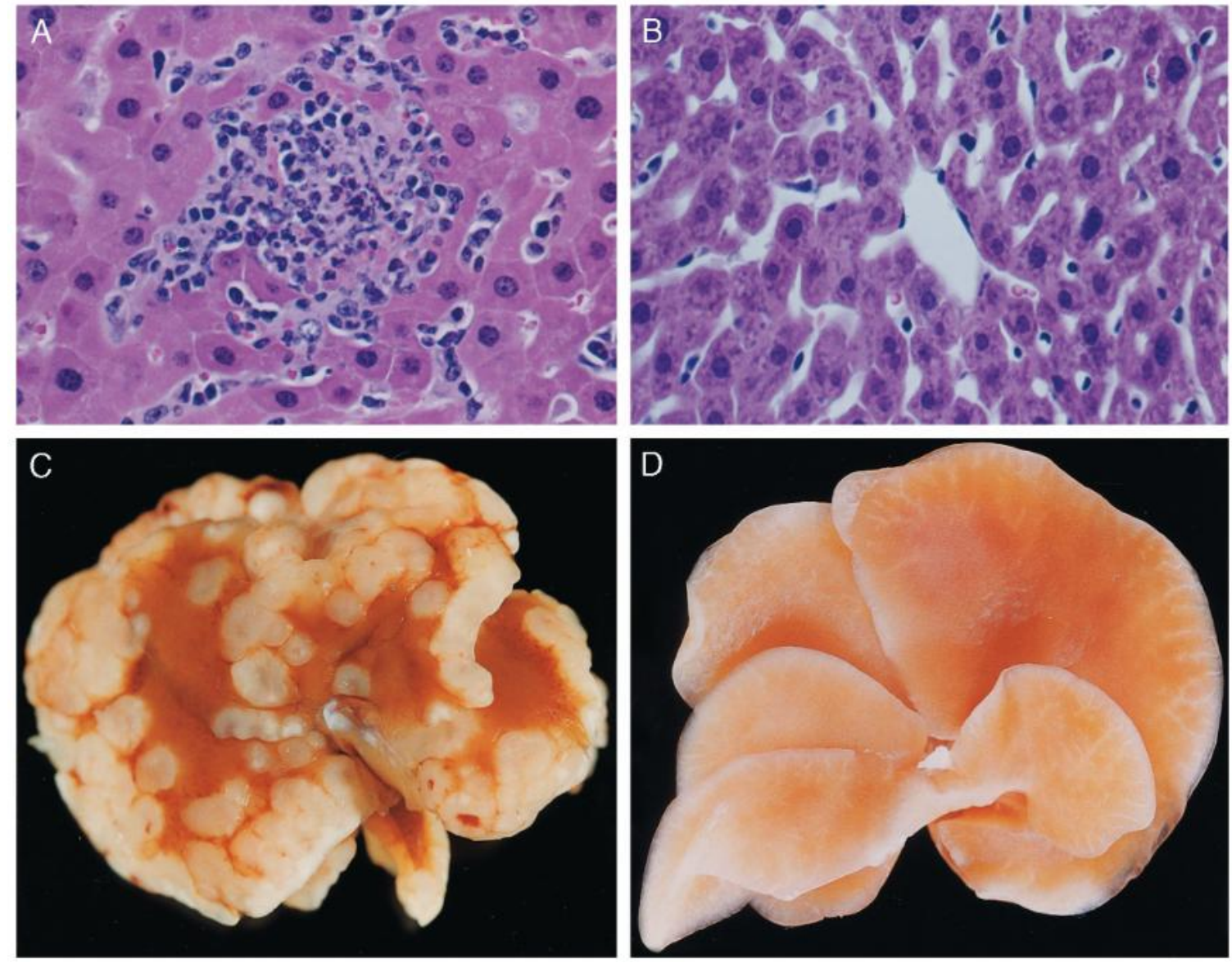

Figure 2.7 Mice colon without ceramide treatment (A,C), mice colon histology with Ceramide treatment (B,D) [30].

In addition to the protective properties of ceramide, SM is also believed to have applications against skin cancer by reducing the formation of radical oxygen species following UV exposure. Exogenous SM is believed to be passively incorporated into the outer leaflet of the plasma membrane, where SM can provide integrity of the plasma membrane [32]. SM is also believed to play a role in degrading GM1 Ganglioside and cholesterol-rich microdomains (i.e lipid rafts) found within the plasma membrane (See figure 2.8) [32]. These lipid rafts have been found to generate damaging radical oxygen species following UVA irradiation [33]. The formation of radical oxygen species has been found to cause DNA damage and potentially lead to the progression of cancer [34]. 
SM capacity to degrade these lipid rafts before the KRTs are exposed to UV radiation could potentially decrease the formation of radical oxygen species following UV exposure, leading to less UV induced DNA damage. This could support SM as an anticancer therapy by inhibiting the production of these radical oxygen species which should lead to less DNA damage following UV radiation [34].

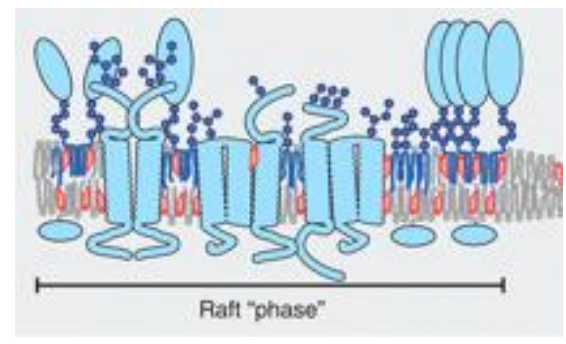

Figure 2.8 Example of a lipid raft microdomain [35].

\subsection{Human p21 Protein}

\subsubsection{Overview}

Human p21 protein participates in cell cycle arrest following DNA damage allowing for DNA repair or apoptosis. The cyclin-dependent kinase inhibitor 1 protein, also known as p21, is mediated by the tumor suppressor gene p53 and inhibits cyclin/cyclin-dependent kinase activity [36]. The human ras gene family is composed of at least three members, including $\mathrm{H}-r a s, \mathrm{~K}-r a s$ and $\mathrm{N}$-ras which are responsible for encoding closely related proteins called p21 [37]. This p21 gene is believed to be the link between the activation of the tumor suppressor gene p53 and the resulting suppression of the $\mathrm{G}_{1}$ growth phase [37]. Subsequent studies of inhibiting $\mathrm{p} 21$ expression found that the $\mathrm{G}_{1}$ growth phase was not inhibited following p53 activation [36]. In addition to the role played by p21 in causing cell cycle arrest, p21 has also been attributed to coordinating with the DNA repair process. PCNA has been identified to activate the DNA polymerase $\delta$, which is involved in both DNA replication and repair [38]. Evidence has been found 
supporting p21 directly binding to PCNA and blocking the activation of DNA

polymerase $\delta$ [38]. These results provide strong evidence that $\mathrm{p} 21$ has an essential role in p53 mediated cell cycle arrest and DNA repair, making p21 an ideal DNA damage biomarker.

\subsubsection{Interactions with Cyclin-CDKs}

The cellular growth process of eukaryotic cells involves a growth and replication phase, known as interphase, which is responsible for production of new organelles, proteins and replication of DNA. This phase is further divided into a $\mathrm{G}_{1}, \mathrm{~S}, \mathrm{G}_{2}$, and $\mathrm{M}$ phase which are characterized by cell growth, chromosome duplication, further growth and division phase respectively. Certain DNA damage checkpoints use damage sensor proteins including ATM, ATR, Rad17-RFC complex and the 9-1-1 complex to detect DNA damage [39]. Following detection of DNA damage, signal transduction cascades employ Chk1, Chk2 and Cdc25 phosphatases, which activate p53 and inactivate cyclindependent kinases to induce cell cycle arrest [39]. Checkpoints include the progression from G1 to S phase, the intra-S checkpoint and G2 to M checkpoint [39]. Activation of a checkpoint either leads to DNA repair mechanisms, including direct repair, base excision repair, double strand break repair, cross link repair and nucleotide excision repair [39]. Failure to adequately repair DNA leads to apoptosis, which ensure that sever damage or deregulated cells are destroyed [39]. These checkpoints help ensure that DNA replication and chromosome segregation are completed with high accuracy [40].

The activation of these checkpoints requires a mechanism for inducing cell cycle arrest to allow for DNA repair or apoptosis. The p21 protein can bind to certain cyclin dependent kinases (Cdks) and can prevent the phosphorylation of Rb by cyclin A-Cdk2, 
cyclin E-Cdk2, cyclin D1-Cdk4, and cyclin D2-Cdk4 complexes [41]. Further experiments with p 21 have found that $\mathrm{p} 21$ can inhibit nearly every member of the cyclin/CDK family [41]. These cyclins are responsible for growth and development during cell division. The D-type cyclins are activated due to mitogenic signals, leading to the assembling of CDK4 and CDK6 during the G1 phase [42]. CDK activating kinases (CAK) are required to activate these CDKs to allow for subsequent downstream phosphorylation. Progression to further growth phases requires that cyclin D-CDK phosphorylate $\mathrm{Rb}$ and sequester cyclin inhibitors including p21 (See figure 2.9) [42]. The role of p21 in preventing cyclin kinase activity and $\mathrm{Rb}$ phosphorylation provides evidence to indicate that $\mathrm{p} 21$ has an essential role in controlling cell cycle progression.

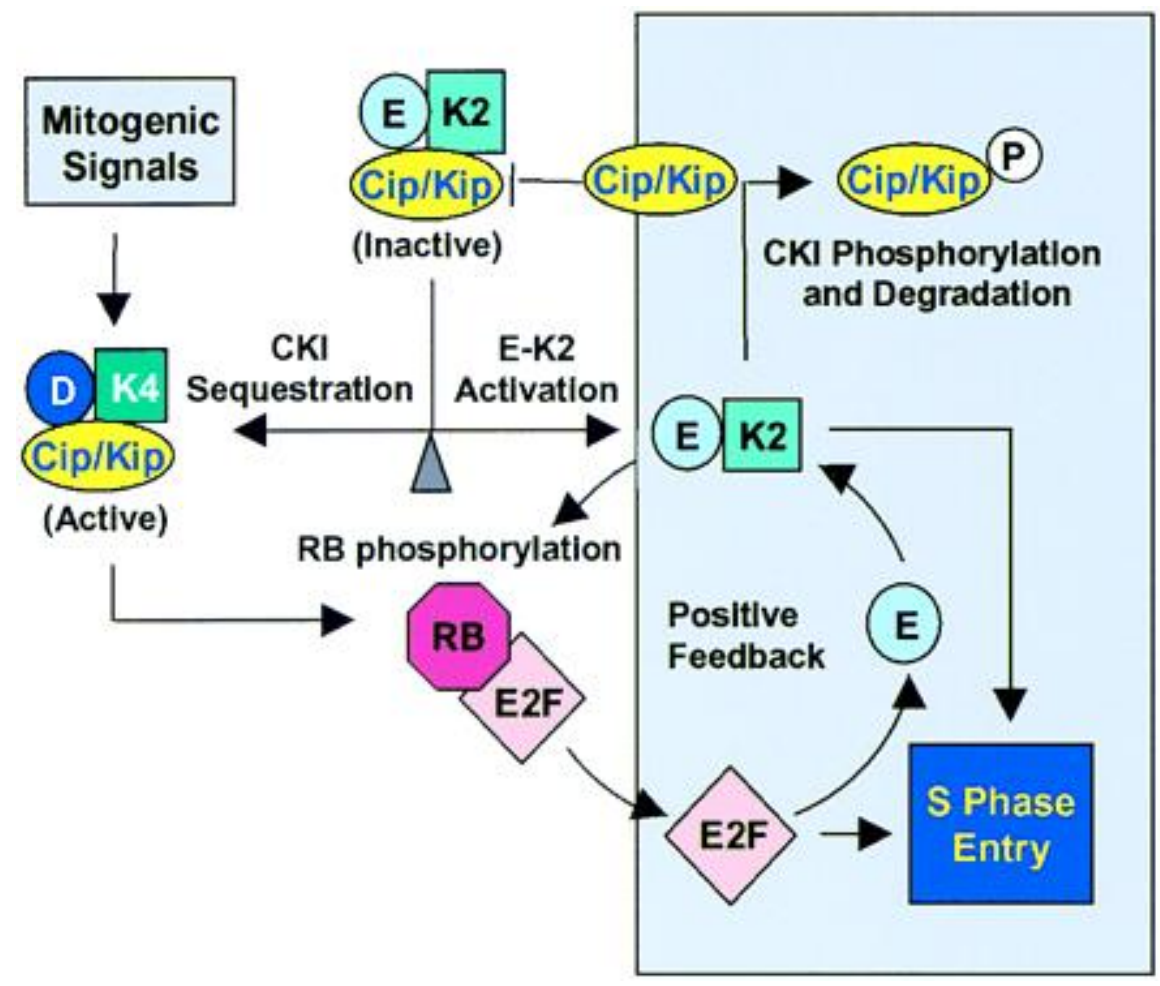

Figure 2.9 Roles of CDK, RB and p21 (Cip) in cell cycle progression [42]. 


\subsubsection{Interactions with PCNA}

The process of DNA replication in eukaryotic cells is an involved process with mechanisms to repair DNA errors. DNA replication is typically very accurate and proceeds at 2900 base pairs per minute [43]. However, DNA legions can lead to replication failure, requiring mechanisms to address these damaged regions [43]. The proliferating cell nuclear antigen (PCNA) is a circular protein that encompasses DNA and helps ensure genomic integrity by recruiting other factors to regions of DNA instability or damage [43]. PCNA is part of the DNA sliding clamps that are composed of two similar globular domains, linked by interdomain connecting loops [43]. This PCNA ring is recruited in regions of DNA damage and will then attach polymerases, including DNA polymerase $\delta$, firmly to DNA thereby increasing the productivity of DNA polymerases from dozens to thousands of nucleotides per minute [43]. The role PCNA has on recruiting factors and increasing polymerase activity make PCNA an essential factor in DNA damage repair.

The p21 protein is responsible for regulating PCNA following DNA damage. The binding of PCNA to DNA is mediated by the $\mathrm{C}$ terminal of the PIP box, where p21 acts as a competitive inhibitor thereby blocking the surface of PCNA from recruiting polymerases [43]. Factors prohibited from PCNA binding following p21 binding include polymerase $\delta$, FEN-1, chromatin remodeling factor WSTF, repair protein XPG and DNA methyltransferase [43]. This suggests that high expression of nuclear p21 expression will cease DNA repair processes, allowing PCNA is interact with p33 and potentially conduct apoptosis [43]. The p33 pathway binds to the N-terminal of PIP box, and has been show to increase over tenfold in the presence of UV irradiation and induce apoptosis [43]. The 
binding of the $\mathrm{C}$ terminus of PCNA to inhibit the DNA repair pathway and binding of the $\mathrm{N}$ terminus to induce apoptosis provide a regulatory means of $\mathrm{p} 21$ altering competitive binding to determine the cell's faith [43]. The role p21 has in directly inhibiting cell growth and regulating apoptosis through PCNA inactivation make p21 an ideal marker to assess UV induced DNA damage.

\subsection{Human p53 Protein}

The tumor suppressor gene p53 is part of the regulation process to prevent oncogenesis. This tumor suppressor p53 protein can bind to the T antigen of SV40, which has been found to inhibit viral replication, DNA polymerases (including $\alpha$ ), and ATP activated helicase activity [44]. This $\mathrm{p} 53$ protein also binds nonspecifically to DNAcellulose [44]. In particular, the p53 interact with PIP boxes on PCNA [44]. Although it's not clear what the nature of the interactions with PCNA, it is clear that p53 does have an essential role in preventing genome mutations [44]. Mutations in the p53 gene is the most commonly observed genetic deviation noted in human cancers [45]. These mutated p53 proteins have been found to lose their affinity to binding DNA, which supports the premise that the process of $\mathrm{p} 53$ binding to DNA is critical to its function as a tumor suppressor [45]. In addition, sustained cell cycle arrest of $\mathrm{G}_{2}$ phase of replication could only be maintained when p53 was present in the cell and transcriptionally activating p21 [46]. Knockout of either p53 or p21 has been found to lead to the progression of mitosis in cells expressing DNA instability [46]. The significant number of p53 mutations associated with cancerous cells, the processes of DNA binding of p53 and the role of activating the tumor suppressing p21 make p53 another DNA damage marker that should be expressed in the presence of UV induced DNA damage [46]. 


\subsection{Overview and Scope of Thesis}

UV exposure is a serious problem leading to millions of new NMSC cases each year. Limitations with sunscreen, including a number of toxic side effects, have sparked interest in safer methods to prevent UV induced DNA damage. Previous work done with bovine SM have shown great promise in preventing other types of human cancer, with particular emphasis on human colon cancer. This has sparked interest if this SM component could also provide protection against NMSC. Bovine SM could potentially provide UV protection through preventing the formation of DNA damaging radical oxygen species during UV exposure, or helping induce apoptosis through the formation of the tumor suppressor ceramide. In order to test the efficacy of SM, human KRTs were gown in vitro in order to test SM treatment prior to UV exposure. UV induced DNA damage was assessed via the expression of two of the most predominant DNA damage biomarkers, p21 and p53. The p21 has includes both cyclin kinase inhibiting to prevent cell growth and interactions with PCNA to halt DNA repair and induce apoptosis. The role p53 has is more ambiguous, though p53 is the most mutation gene in cancerous cells, upstream of p21 and believed to interact with DNA to regulate cell cycle. Both p53 and p21 are essential to maintaining cell cycle arrest following DNA damage, giving time for cell to repair DNA damage or commit to apoptosis, making p21 and p53 ideal markers to assess UV induced DNA damage. Both of these DNA damage biomarker nuclear expressions are assessed following treatment and UV exposure. The data is then analyzed to determine if any evidence exists to support SM as having any potential to protect against UV induced NMSC. 


\section{Chapter 3: Methods for Protocol}

\subsection{Summary}

KRTs were cultured using keratinocyte growth media and were plated into 8 well plates specifically designed for imaging with an inverted microscope. SM solution was added to half of the KRTs and the cells were allowed to incubate for 24 hours in this media. A randomized distribution of SM treated groups was used to minimize any effects caused between plates. Following the 24 hour incubation, the SM media was removed and replaced with SM free media prior to UV exposure. The SM media was removed and replacement with a fresh non-SM media prior to UV exposure to ensure that SM still present in the media solution wasn't reflecting the UV radiation. A UV lamp was used in a controlled setting using appropriate personal protective equipment to expose KRTs to 302nm UV radiation. An appropriate time was calculated to expose the KRTs to $40 \mathrm{mj} / \mathrm{cm}^{2}$. Following UV exposure, the KRTs were incubated for an additional 24 hours prior to fixing the cells. Four KRT groups were tested in the described manner, consisting of no SM and no UV (SM (-) UV (-)), no SM and UV (SM (-) UV (+)), SM and no UV (SM (+) UV (-)) and SM and UV (SM (+) UV (+)) (See Figure 3.1). 


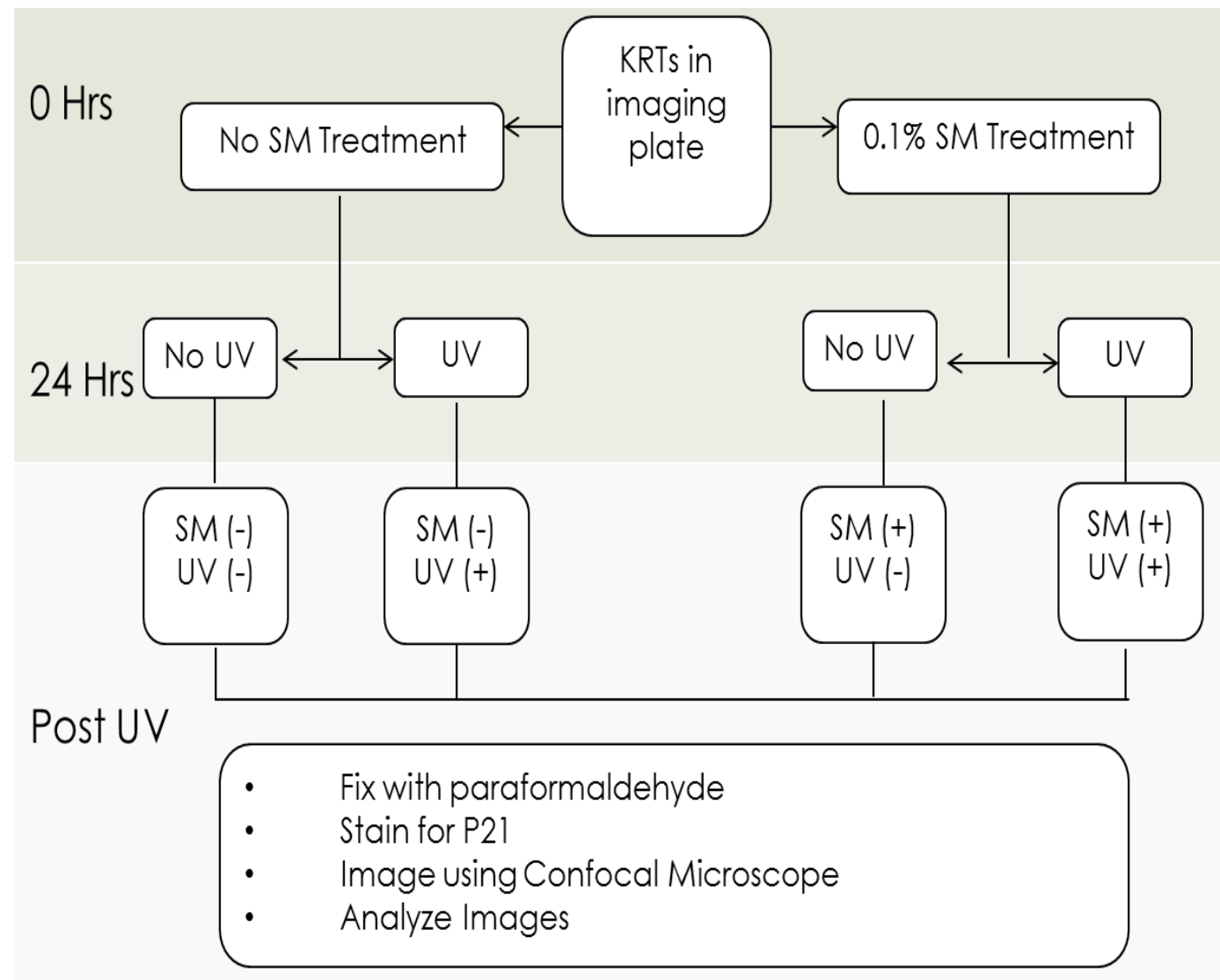

Figure 3.1 Flowchart of the KRTs protocol for each treatment group

KRTs were fixed with $3.7 \%$ paraformaldehyde following washing. All washes were done three times with PBS. The paraformaldehyde was left in the cells for 15 minutes. A solution of triton-x was added to the KRTs to permeabilize the plasma membrane and allow for the diffusion of reagents into the cell. This solution of triton- $\mathrm{X}$ was left on for 15 minutes. The desired biomarker of interest determined the following blocking, primary and secondary reagents. Procedures used in this experiment included staining for p21, p53 and both p21 and p53 simultaneously (dual staining). Blocking was added to each well and left on overnight. Removal of the blocking was followed by the addition of the primary p21 and/or p53 antibody. This primary was left on for about 9-12 hours before being washed. Observation of $\mathrm{p} 21$ or $\mathrm{p} 53$ required the addition of the 
secondary Alexa Fluor 488 or Alexa Fluor 488 and 647 for dual staining. The secondary was removed after an hour in the wells and then Hoechst stain [Life Technologies, H21486] was left on for 15 minutes and was used to visualize the nucleus of each cell (See Table 3.1). Imaging was performed on a confocal microscope at $40 \mathrm{X}$ allowing for simultaneous imaging of p21 and Hoechst. Three representative images were taken for each well in each of the four plates (total of 32 wells) and nuclear expression of p21 was determined by overlapping Hoechst and p21 fluorescence. An automated program determined the number of KRTs using the Hoechst stain and ImageJ was used to manually count cells with p21 positive expression [2]. The ratio of the number of cells with nuclear p21 expression to the total number of cells were taken for each well, and ttesting was used to determine differences between each group.

Table 3.1 Summary of reagents and concentrations within these experiments

\begin{tabular}{|l|l|l|l|l|l|}
\hline Process & Reagent & Concentration & $\begin{array}{l}\text { Duration } \\
\text { Fixing }\end{array}$ & $\begin{array}{l}\text { Dual or Single } \\
\text { Staining }\end{array}$ & $\begin{array}{l}\text { Vendor and } \\
\text { Catalog No. }\end{array}$ \\
\hline Permeabilization & Triton-X-100 & $0.1 \%$ & 20 min & Both & $\begin{array}{l}\text { Invitrogen } \\
\text { HFH10 }\end{array}$ \\
\hline Blocking & $\begin{array}{l}10 \% \text { Normal Goat } \\
\text { Serum }\end{array}$ & $1 \%$ & Overnight & Both & $\begin{array}{l}\text { Life Technologies } \\
500622\end{array}$ \\
\hline & $\begin{array}{l}87.5 \mathrm{mg} / \mathrm{ml} \text { Normal } \\
\text { Donkey Serum }\end{array}$ & $1 \%$ & Overnight & Dual & Abcam ab7475 \\
\hline Primary & p21 & $1: 400$ & $9-12$ hours & Single & Abcam ab18209 \\
\hline & p21 & $1: 400$ & $9-12$ hours & Dual & Abcam ab184640 \\
\hline & p53 & $1: 400$ & $9-12$ hours & Both & $\begin{array}{l}\text { Life Technologies } \\
710294\end{array}$ \\
\hline Secondary & AF 488 & $1: 400$ & 1 hour & Both & $\begin{array}{l}\text { Life Technologies } \\
\text { A11008 }\end{array}$ \\
\hline & AF 647 & $1: 400$ & 1 hour & Dual & Abcam ab150107 \\
\hline Hoechst & p53 & $1: 400$ & 15 min & Both & $\begin{array}{l}\text { Life Technologies } \\
\text { H21486 }\end{array}$ \\
\hline
\end{tabular}




\subsection{Keratinocyte Culturing}

Aseptic technique was crucial during these experiments and was preformed within a sterile hood. These experiments used primary human epidermal KRTs which were isolated from normal, neonatal foreskin (PCS-200-010, ATCC Manassas, VA). These KRTs were then cultured within a humid incubator. The incubator was set at $37^{\circ} \mathrm{C}$ with approximately 5\% carbon dioxide. The growth media used for the control and SM groups consisted of a Keratinocyte Growth Kit (PCS-200-040, ATCC, Manassas, VA) mixed with one bottle of Dermal Cell Basal Medium (PCS-200-030, ATCC, Manassas, VA), 0.5mL of Penicillin-Streptomycin-Amphotericin (PCS-999-002, ATCC, Manassas, VA), 0.5mL of Gentamicin-Amphotericin (PCS-999-025, ATCC, Manassas, VA) and 0.5mL of Phenol Red (PCS-999-001, ATCC, Manassas, VA) and passing the mixture through a $0.22 \mu \mathrm{m}$ filter. KRTs were cultured in 8 -well coverglass plates which were specially designed for viewing with an inverted microscope. These KRTs were observed every 24 to 48 hours with a brightfield microscope to assess cell morphology, signs of contamination and confluency. The media was also replaced during this period using approximately $0.5 \mathrm{ml}$ of media in each well. T-75 flasks of KRTs with approximately $70 \%$ confluency were passed into four of the eight well plates.

Half of the plates were treated with SM media 24 hours prior to UV exposure. Solutions of $0.1 \%$ bovine SM were prepared and dissolved within keratinocyte growth media for use with KRTs. Stock bovine SM was initially a yellowish powder that was removed via tweezers and weighed to obtain the appropriate volume to create a solution of $0.1 \%$ SM. KRTs media was then added to the weighed SM through a $0.22 \mu \mathrm{m}$ filter and the SM was dissolved into the solution via warming and vortexing. This SM media was 
good for a month before being replaced with new media. This study consisted of four treatment groups that were randomized as shown in Figure 3.2. Cells with odd morphology or contamination were not used during to acquire data during the course of this study.

\begin{tabular}{|l|l|}
\hline SM (+) & SM (-) \\
\hline SM (-) & SM (+) \\
\hline SM (+) & SM (-) \\
\hline SM (-) & SM (+) \\
\hline
\end{tabular}

Figure 3.2 Randomized group distribution for each plate. Yellow indicates UV.

\subsection{UV Treatment}

UV treatment was performed in the same aseptic hood used to add culture media. All of the cells had their current media removed and replaced with SM free media, ensuring that any UV protective effects on the SM treated group were the result of SM incorporated into the KRTs and not the result of SM in solution. The UV box used to safely enclose the plates was created out of black Delrin plastic sheets, which form a rectangular box with removable top and bottom. The box is composed of four walls that were permanently glued together and a removable top and bottom component. The top component had a rectangular hole that allowed for the placement of the UV lamp while the bottom component was designed to allow for the sliding of a tray holding a plate needing UV exposure. An ABS plastic tray was designed to hold on plate at a time, and worked in conjunction with a plate cover that ensures only half the plate receives UV radiation (See figure 3.3). 


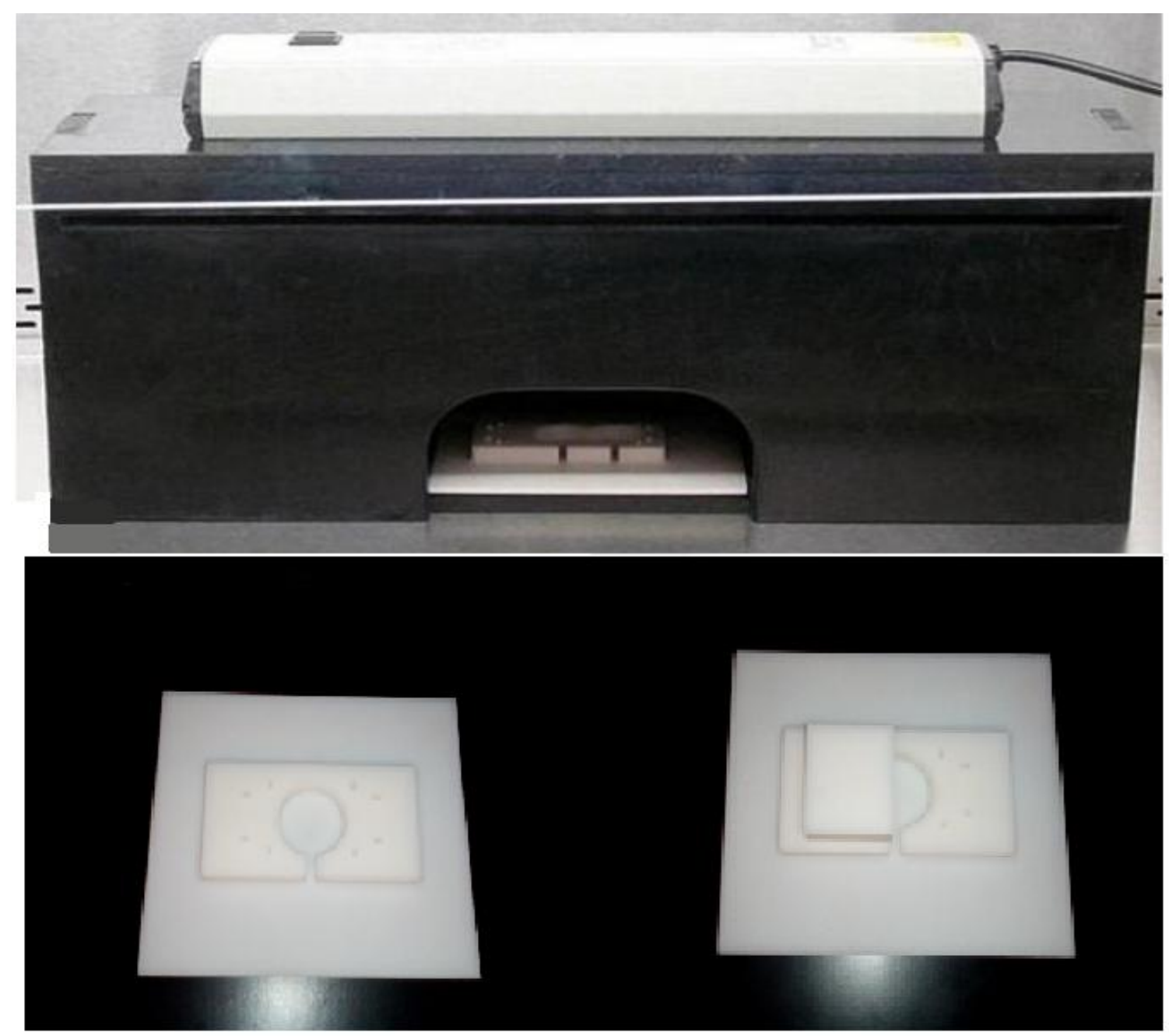

Figure 3.3 UV box and lamp (top) and plate tray with and without cover (bottom). The UV box, UV lamp and UV sensor were sterilized with IPA cleaning solution.

and were brought into the sterile hood. The UV box and lamp were assembled within the hood, and the lamp (95-0251-01, UVP, LLC, Upland, CA) was activated to 302nm for approximately five minutes. Then the UV sensor (S120UV, ThorLabs, Newton, NJ) was connected to the power meter (PM100,ThorLabs, Newton, NJ), was placed under the UV lamp and the average UV exposure was calculated. The exposure time was then determined from the area of the sensor and the average intensity to expose the cells to $40 \mathrm{mj} / \mathrm{cm}^{2}$ of radiation, which prior work found to be the optimum dose to observe 
differences in DNA damage biomarker expression and simulates typical sunburn conditions $[7,47]$.

$$
\text { Exposure time }(\mathrm{sec})=\frac{\text { Prescribed Dose }\left(\mathrm{mj} / \mathrm{cm}^{2}\right)}{(1 \mathrm{~mW} / 1000 \mu \mathrm{W}) * \text { Measured irradiance }\left(\mu \mathrm{W} / \mathrm{cm}^{\wedge} 2\right)}
$$

Where irradiance was calculated by taking the average intensity of the UV sensor and dividing by the sensor area of $0.7088 \mathrm{~cm}^{2}$ (diameter of $0.9 \mathrm{~cm}$ ). The exposure time was normally around 2 minutes based on the condition of the UV lamp. The sensor was then removed, and a plate was placed with the holding tray, a plastic cover was inserted over the half of the plate that was not to receive UV radiation and the plate was positioned under the lamp for the previously calculated amount of time. This was repeated for each plate and the plates were returned to the incubator. The UV box, lamp and sensor were disassembled and return to their proper storage area.

\subsection{Fixation and Immunoflourescence Staining}

Following UV exposure, the KRTs were given 24 hours to begin their DNA damage repair pathways. After this 24 hour post-UV incubation period, each of the eight well plates had their media contents aspirated out and were gently washed three times with PBS. All solutions were added with pipettes by adding solutions drop wise on the side of the wells. Then $200 \mu 1$ of $3.7 \%$ paraformaldehyde was added to each well to fix the cells. The paraformaldehyde was left on each plate for approximately 15 minutes before being removed and washed three additional times with PBS. The KRTs were then premeabilized by adding $0.1 \%$ of the stock triton-x-100 solution diluted in PBS to each well. Then $200 \mu 1$ of triton-x working solution was added to each well, left on for about 20 minutes and was removed and washed three times with PBS. The appropriate blocking serum was diluted to $1 \%$ in PBS and $200 \mu$ of this blocking solution was added to each 
well. The blocking solution was left on for at least eight hours to help minimize offsite binding of the secondary and to ensure the maximum ratio of signal to noise. The blocking solution was then removed and washed three times with PBS before primary was added. Primary consisted of a 1/400 dilution of desired antibody in PBS and $200 \mu$ of this solution was left on the cells for about 8-10 hours. The primary was removed washed three times with PBS and the appropriate secondary was added at the same 1/400 dilution. Table 3.2 below lists the primary and secondary antibodies that were used in these experiments. Note that the primary and secondary antibodies were different for the p21, p53 and both $\mathrm{p} 21$ and p53 stains. The antibodies used for $\mathrm{p} 21$ were not found to react with the p53 antibodies and vice versa. As a result, staining for both p21 and p53, referred here as dual staining, had appropriate blocking solutions added simultaneously for both $\mathrm{p} 21$ and $\mathrm{p} 53$ during the blocking step. The primary regents for $\mathrm{p} 21$ and $\mathrm{p} 53$ were added together during the primary phase and both secondary dyes were also added together during the secondary step. The secondary was removed following an hour, rinsed three times with PBS and Hoechst stain $(5 \mu \mathrm{g} / \mathrm{ml})$ was diluted to $0.05 \%$ and left on the wells for 15 minutes. The wells were then washed three more additional times and $200 \mu 1$ of PBS were left on each well. 
Table 3.2 List of Antibodies and Fluorescent Dyes used for each staining procedure.

\begin{tabular}{|c|c|c|c|}
\hline $\begin{array}{c}\text { Antibodies and } \\
\text { Fluorescence Dyes }\end{array}$ & $\begin{array}{c}\text { Staining } \\
\text { Application }\end{array}$ & $\begin{array}{c}\text { Antibody } \\
\text { Concentration }\end{array}$ & Vendor and Catalog No. \\
\hline $\begin{array}{c}\text { Anti p21 raised in } \\
\text { Mouse }\end{array}$ & Dual Staining & $1: 400$ & Abcam ab184640 \\
\hline $\begin{array}{c}\text { Anti p21 raised in } \\
\text { Rabbit }\end{array}$ & p21 & $1: 400$ & Abcam ab18209 \\
\hline $\begin{array}{c}\text { Anti p53 raised in rabbit } \\
\text { Donkey Anti-Mouse } \\
\text { Alexa Fluor 647 }\end{array}$ & $\begin{array}{c}\text { Either p53 or Dual } \\
\text { Staining }\end{array}$ & $1: 400$ & $\begin{array}{c}\text { Life Technologies } \\
710294\end{array}$ \\
\hline $\begin{array}{c}\text { Goat Anti-Mouse Alexa } \\
\text { Fluor 488 }\end{array}$ & $\begin{array}{c}\text { p21, p53 or Dual } \\
\text { Staining }\end{array}$ & $1: 400$ & Abcam ab150107 \\
\hline Hoechst & $\begin{array}{c}\text { p21, p53 or Dual } \\
\text { Staining }\end{array}$ & $2 \mu \mathrm{g} / \mathrm{ml}$ & $\begin{array}{c}\text { Life Technologies } \\
\text { A11008 }\end{array}$ \\
\hline
\end{tabular}

\subsection{Confocal Imaging}

Images were then obtained for each well following completion of the immunofluorescence protocol with an Olympus FluoView FV1000 confocal microscope (Olympus America, Centerville, PA). The FluoView Software was configured to apply optical filters for DAPI, Alexa Fluor 488 for either p21 or p53 staining. Simultaneous staining of p21 and p53 required optical filters for DAPI, Alexa Fluor 488 and Alexa Fluor 647. The 40x oil immersion objective was used to image the wells after securing the plates within the proper mount on the stage. The cells were then put into focus using widefield fluorescence and regions of high confluency near the center of the plates were located. This was necessary because most of the $40 \mathrm{mj} / \mathrm{cm}^{2}$ of UV radiation reached the center of the well, while regions of the plate closer to the wall can potentially deflect UV radiation lowering the effective UV dose. The speed scan was set to $4 \mu \mathrm{s} /$ pixel and image size was set to 512 by 512 . After finding a region of interest, the samples were scanned using "XY Repeat" and were further focused to find the center plane of the nuclei of the 
KRTs. The laser power and HV were optimized for each channel to allow for clear identification of p21 or p53 positive cells without creating too much background. The "Sequential" feature was also used to avoid unnecessary bleed-through of channels. Three locations in each well were selected to effectively sample the entire well. Images were exported as TIFF files and saved for further image analysis.

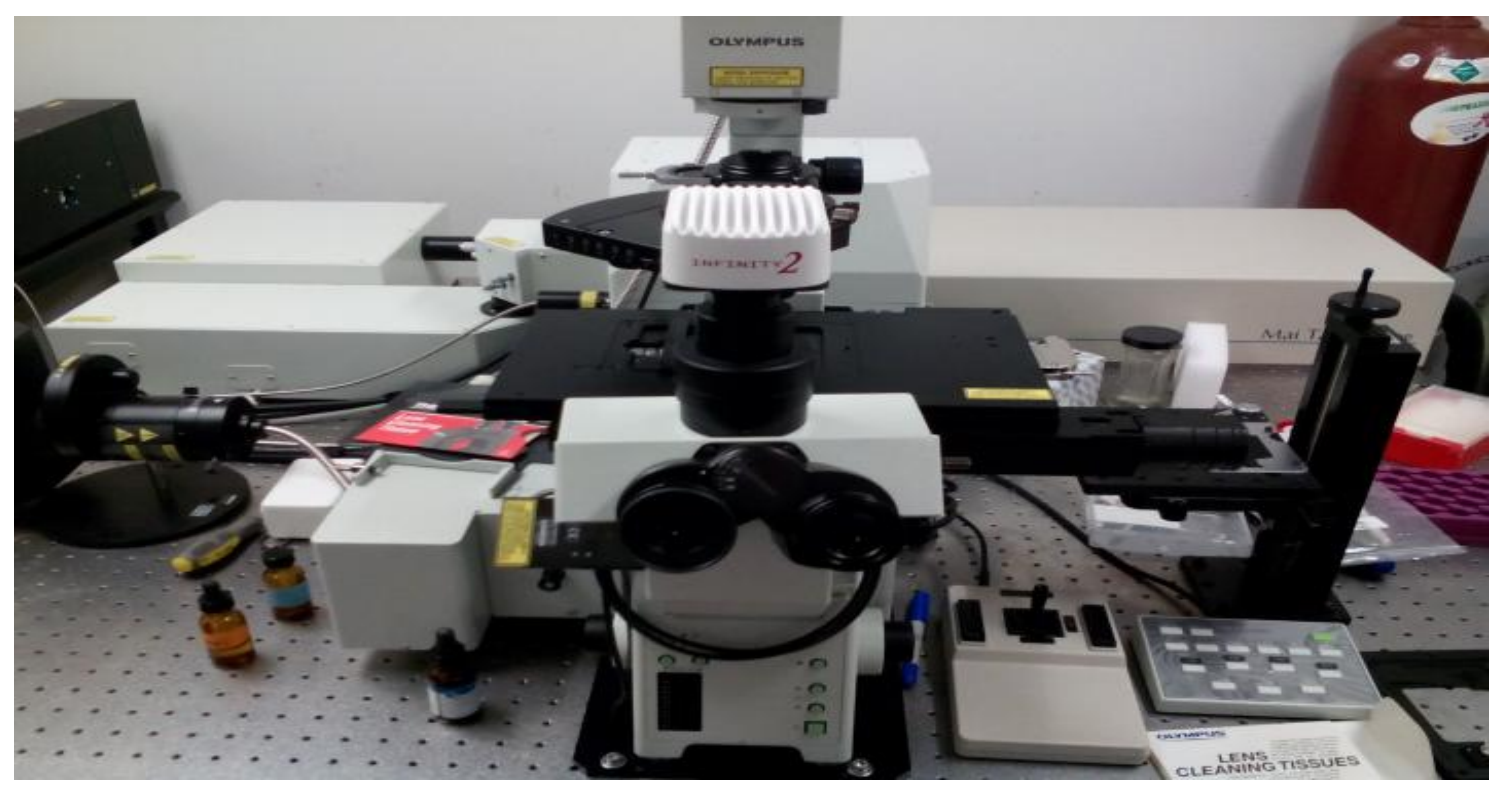

Figure 3.4 The Olympus FluoView FV1000 confocal microscope used for imaging.

\subsection{Image Analysis}

In order to determine the ratio of $\mathrm{p} 21$ or $\mathrm{p} 53$ positive cells within each image, the number of total cells and cells expressing nuclear p21 or p53 must be determined. The IntenseCount program analyzed merged images and was used to determine the total number of cells present in each well [7]. ImageJ was then used to manually place markers in each cell that was found to be p21 or p53 positive. A user identified these positive cells by visual inspection of the nucleus expression compared to expression within the cytoplasm. The cells with clearly higher expression in the nucleus were counted as positive cells and the ratio of number of positive to total number of cells in each image is calculated. The ratio was averaged over every image taken in the well to create one data 
point for the well. Difficulties in maintaining confluency within the center of the well following UV treatment and the potentially harsh process of staining limited the number of samples obtained for the course of these experiments. As a results, the final sample size was $n=8$, which allowed for $t$-testing between each group $(\alpha=0.05)$ using Microsoft excel. In addition, the differences between both UV treated groups are compared via ttest $(\alpha=0.05)$ to determine if SM imparts any photoprotective effects. Tukey's test was not employed due to the assumption that every treatment group has equal variances, which was found to not hold true for the control cases. This could be due to the relatively the small sample size of each group and the large variance of KRTs naturally expressing p21 and p53 due to DNA damage independent of UV radiation. 


\section{Chapter 4: Results for Protocol}

\subsection{Preliminary Results}

A number of factors went into optimizing the protocol discussed in the previous section in order to obtain data to potentially support SM protecting against UV induced DNA damage. The first major difficulty in the protocol was maintaining cell confluency in the center of the wells. Harsh treatment while adding reagents or washing during staining destroyed KRTs in the center of the well. The center of the well is the most exposed, both to UV exposure and staining, making these KRTs the easiest to wash off the plate (See Figure 4.1). However, these cells also received $40 \mathrm{mj} / \mathrm{cm}^{2}$ of UV radiation, whereas cells near the edges received less UV exposure, making it necessary to develop new methods to maintain higher confluency near the center of the well. As a result, new pipette techniques were thoroughly researched to ensure that the KRTs were treated gently during staining. The methods adopted included gently dipping solutions on the sides of the well when adding liquid, which improved cell viability considerably.

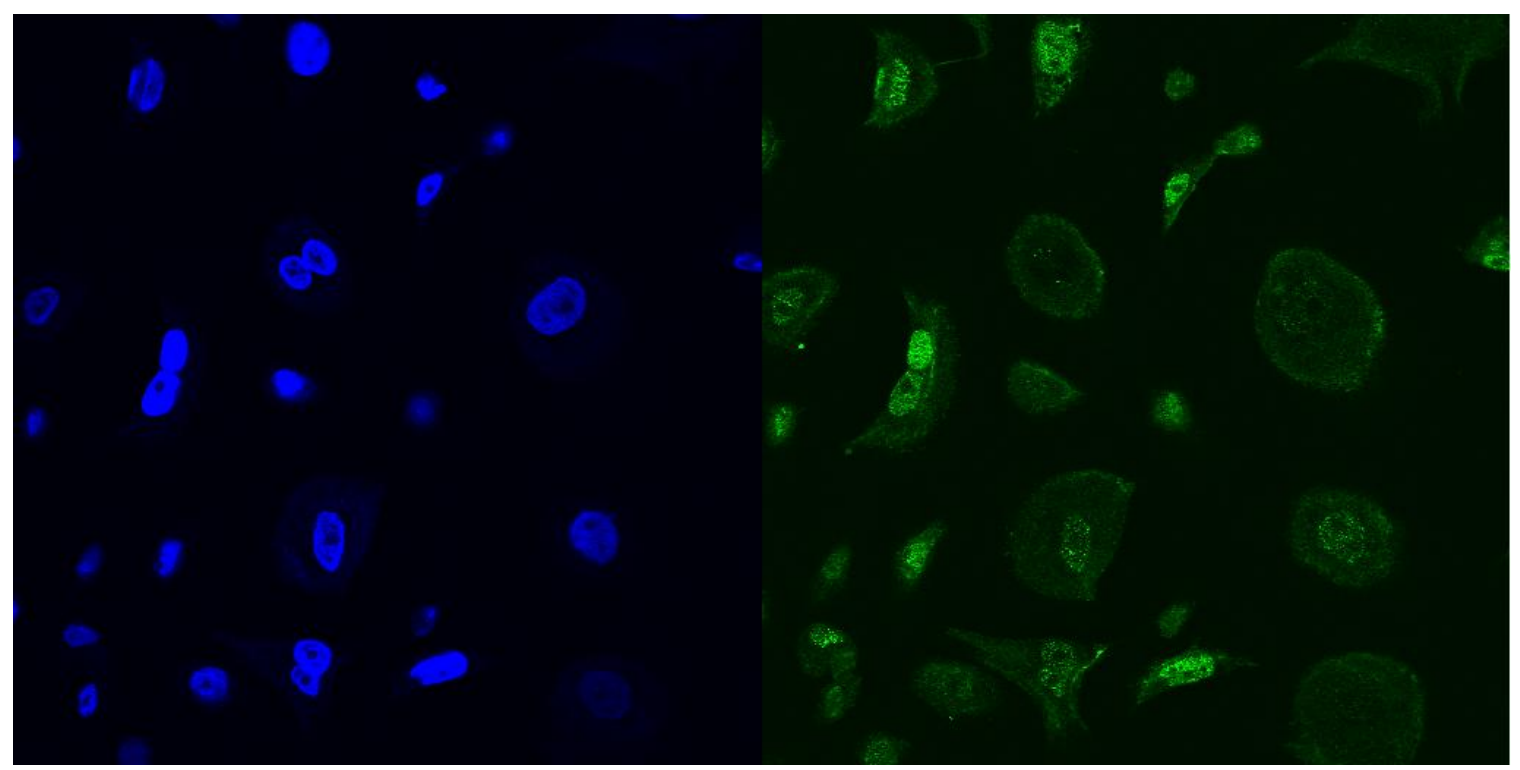

Figure 4.1 Regions of poor confluency near the center of the well. 
Maintaining higher confluency of KRTs was a major step towards evaluating UV induced DNA damage, but a poor signal to noise contrast further limited the usefulness of our data. Pictures obtained with the new methods did increase KRT confluency considerably, but each cell was found to have nuclear expression of Alexa Fluor 488 (See Figure 4.2). This made identification of positive or negative p21 or p53 expressing KRTs impossible, requiring additional work to optimize the stain. Addition research found that the blocking step was insufficient, which is why blocking concentration was increased to $1 \%$ and left on overnight. This did increase the signal to noise ratio and allow for quantification of KRTs with positive and negative p21 or p53 expression.

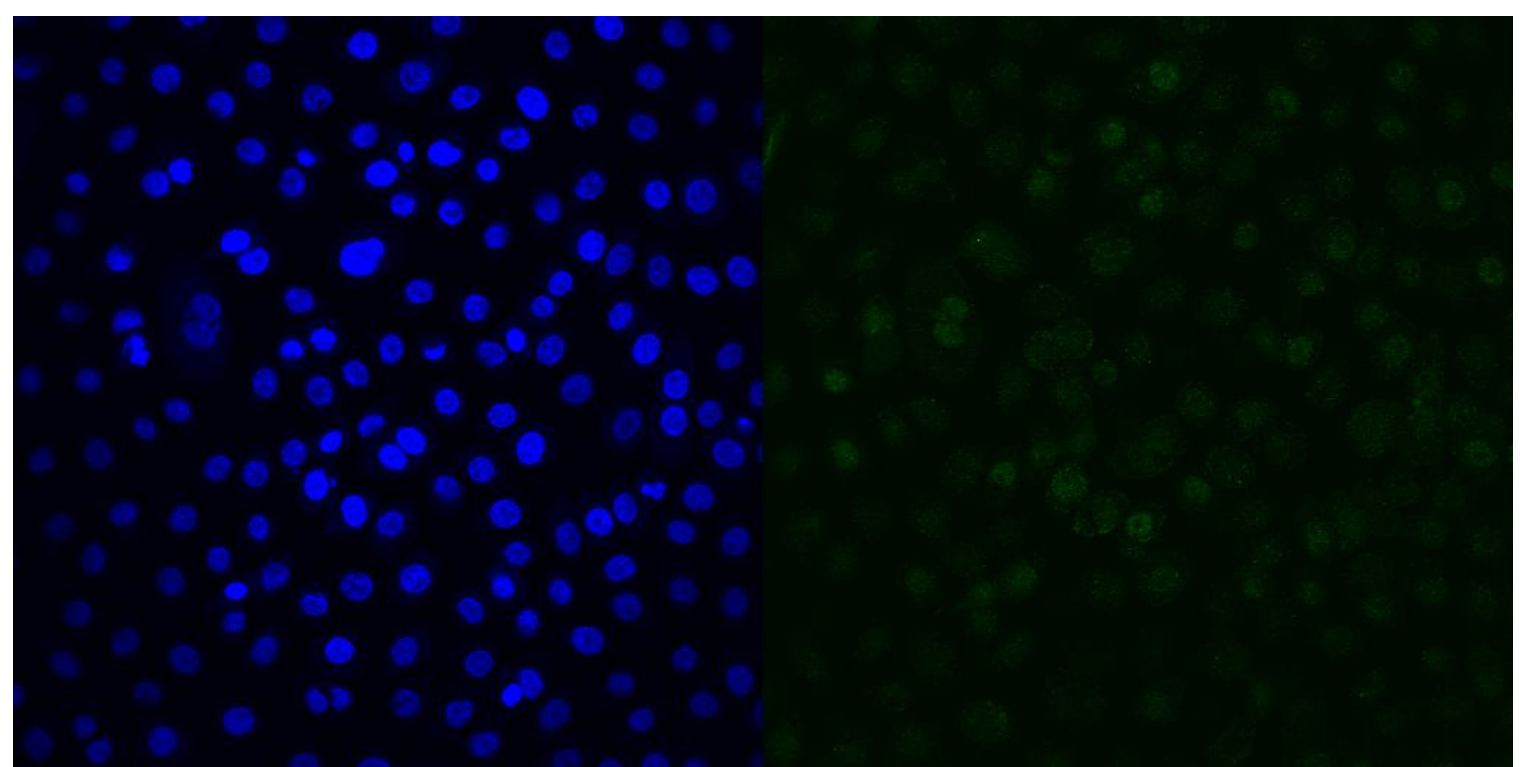

Figure 4.2 Regions of poor signal to noise ratio attributed to insufficient blocking. Another serious problem our lab group encountered was that antibodies sometimes were deficient or impure. One of the problems encountered during dual staining included a bad lot of p21 primary antibody, which required higher laser power to visualize the KRTs. However, the high laser power also created background, which made identification of p21 positive and negative KRTs difficult (See Figure 4.3). Testing the 
primary with various known working secondary stains allowed for identification of the defect within the primary and a replacement was acquired.

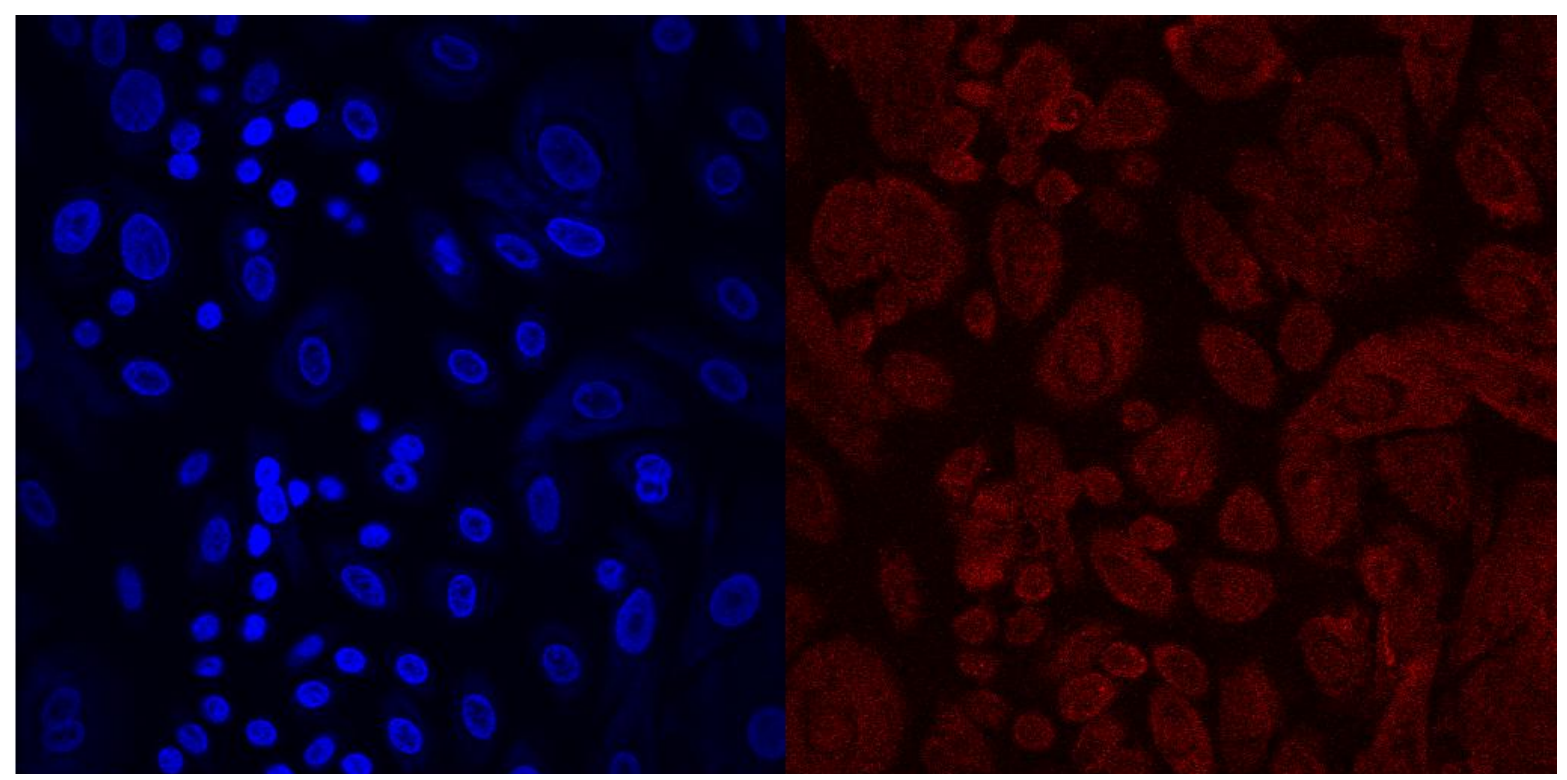

Figure 4.3 Poor binding of the primary antibody.

\subsection{The p21 Results}

\subsubsection{Representative Images}

Representative images taken by the confocal microscope of the four treatment groups are shown in Figure 4.4. The hoechst stain is blue and indicates the location of the nucleus of each cell. The Alexa Fluor 488 is green and binds p21. Typically p21 is found within the cytoplasm, but will be expressed in the nucleus following DNA damage. Therefore, the bright green signal in the nuclear region indicates if the skin cells have taken UV damage. The SM (-) UV (+) group appeared to have the highest ratio of nuclear p21, followed by SM (+) UV (+) and significantly lower expression in the remaining no UV groups. It was also observed that p21 was expressed primarily in the cytoplasm in the UV (-) SM (-) group, but had much higher nuclear localization in UV (+) SM (-) group. 
Hoechst

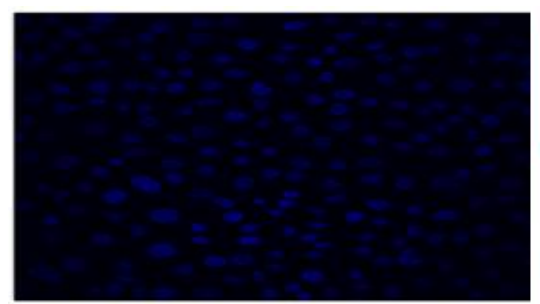

UV (+) SM (-)

UV (-) SM (+)

$\mathrm{UV}(+) \mathrm{SM}(+)$
Alexa Fluor 488
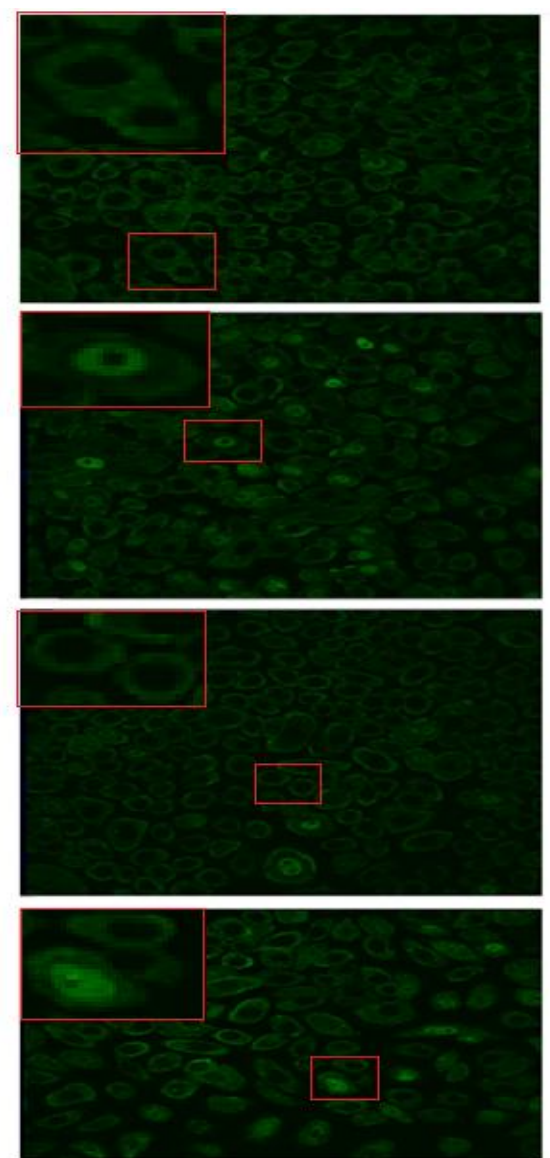

Merged
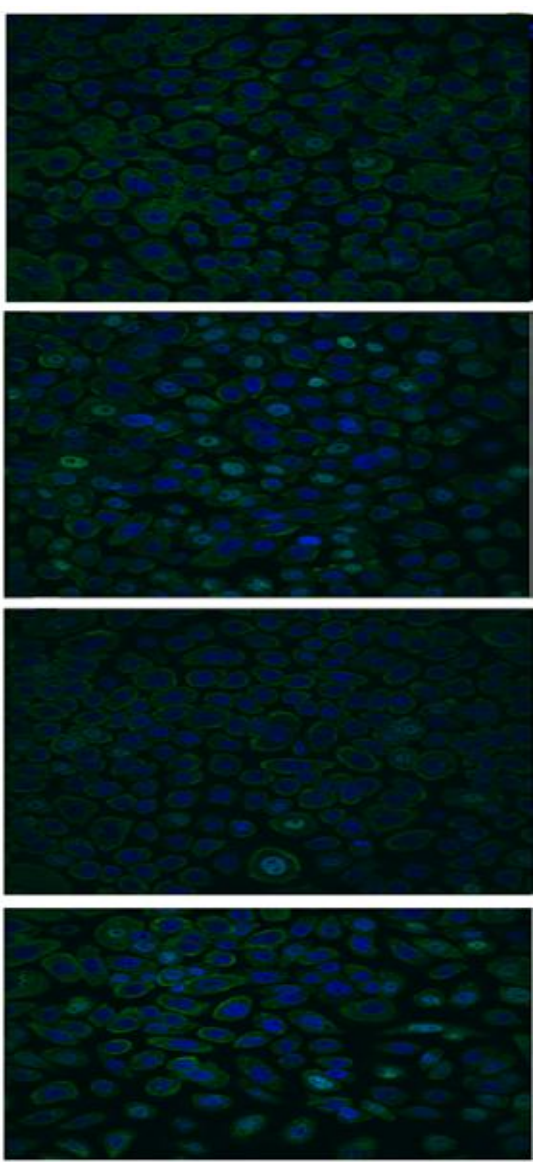

Figure 4.4 UV Treated Sphingomyelin Groups. No SM and no UV treatment (top row), No SM and UV treatment ( $2^{\text {nd }}$ row), $0.1 \%$ Sphingomyelin and no UV treatment ( $3^{\text {rd }}$ row), and $0.1 \%$ Sphingomyelin and UV treatment (last row).Regions in red are magnified KRTs showing p21 positive cells for UV treated KRTs and p21 negative cells for the no UV treated KRTs.

\subsubsection{Raw Data}

The ratio of KRTs expressing p21 were manually counted using imageJ and the IntenseCount program and is shown in table 4.1 below. The same trends noted in the representative images above were seen during the data analysis. The highest expression of p21 positive KRTs were seen with the SM (-) UV (+) group, followed by the SM (+) UV (+), SM (+) UV (-) and SM (-) UV (-) groups. The difference between the both UV groups were significantly more than the difference between the no UV groups. 
Table 4.1 The ratio of $\mathrm{p} 21$ positive cells being expressed in each treatment group

\begin{tabular}{|l|c|c|}
\hline $\begin{array}{l}\text { Treatment } \\
\text { Group }\end{array}$ & $\begin{array}{l}\text { Ratio of p21 Positive } \\
\text { KRTs }\end{array}$ & Standard Error \\
\hline SM (-) UV (-) & 0.045311117 & 0.014518851 \\
\hline SM (-) UV (+) & 0.122167707 & 0.008970801 \\
\hline SM (+) UV (-) & 0.038690553 & 0.007467327 \\
\hline SM (+) UV (+) & 0.084221973 & 0.0092956 \\
\hline
\end{tabular}

\subsubsection{Interpretations}

The ratio of cells expressing nuclear p21 for each group is shown in Figure 4.5.

The SM (-) UV (+) treatment group was found to have the highest ratio of cells expressing nuclear p21, followed by SM (+) UV (+), SM (-) UV (-) and SM (+) UV (-). The data showed a significant difference in the ratio of $\mathrm{p} 21$ expression between both groups at the UV dosage level and both groups without UV exposure. This supports the initial premise that $\mathrm{p} 21$ is an appropriate DNA damage biomarker to observe UV induced DNA damage. No difference between the ratios of cells expressing nuclear p21 was observed between either groups at the no UV dosage level. This does not provide any evidence of SM having any adverse effects on KRTs health, which is important if SM is to ever have any therapeutic application. There was a difference between the UV (-) SM (-) and the UV (+) SM (-) groups. This indicates that UV radiation did induce DNA damage and that p21 was expressed in the nucleus in response to this DNA damage. There was a significant difference between the SM (-) UV (+) and SM (+) UV (+) groups nuclear p21 expression. This decrease in $\mathrm{p} 21$ expression provides evidence of SM providing protection against UV induced DNA damage. 


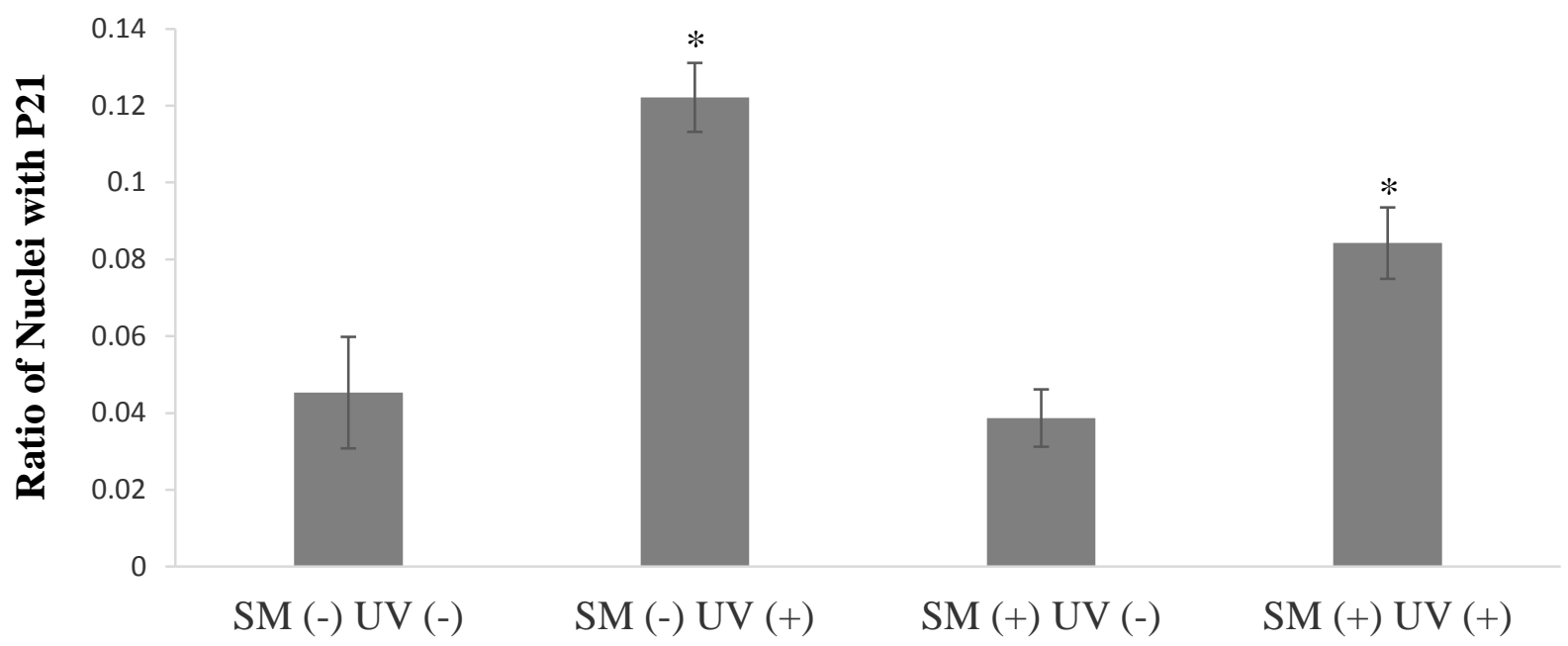

Figure 4.5 UV Treated Sphingomyelin Results. The ratio of cells expressing nuclear p21 compared to the total number of cells in each group is plotted above. $\left(^{*}\right) \mathrm{p}<0.05$; significant difference in ratio of cells expressing nuclear p21.

\subsection{The p53 Results}

\subsubsection{Representative Images}

The results for $\mathrm{p} 53$ follow a very similar trend to $\mathrm{p} 21$. Representative images taken by the confocal microscope of the four treatment groups are shown in Figure 4.6. The hoechst stain is blue and indicates the location of the nucleus of each cell. The Alexa Fluor 488 is green and binds p53. Typically p53 is found within the cytoplasm, but will be expressed in the nucleus following DNA damage. Therefore, the bright green signal in the nuclear region indicates if the skin cells have taken UV damage. As shown in the p21 results, the hoechst stain is blue and the Alexa Fluor 488 is green, with the bright green signal in the nuclear region indicating that the skin cells have taken UV damage. The SM (-) UV (+) group appeared to have the highest ratio of nuclear p21, followed by SM (+) UV (+) and significantly lower expression in the remaining no UV groups. It was also observed that p53 was expressed primarily in the cytoplasm in the UV (-) SM (-) group, but had much higher nuclear localization in UV (+) SM (-) group. 
UV (-) SM (-)

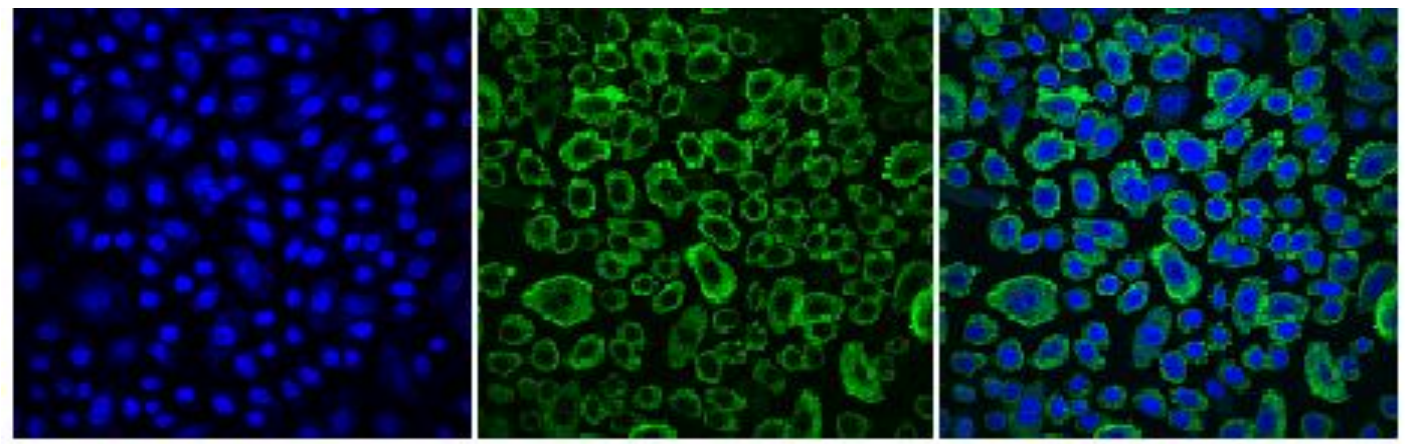

$\mathrm{UV}(+) \mathrm{SM}(-)$
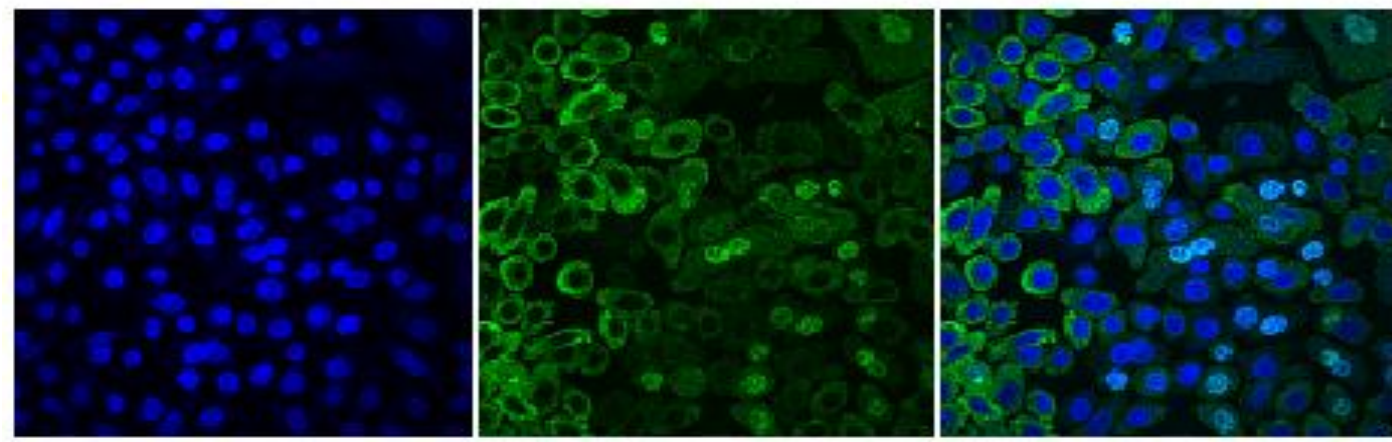

UV (-) SM (+)
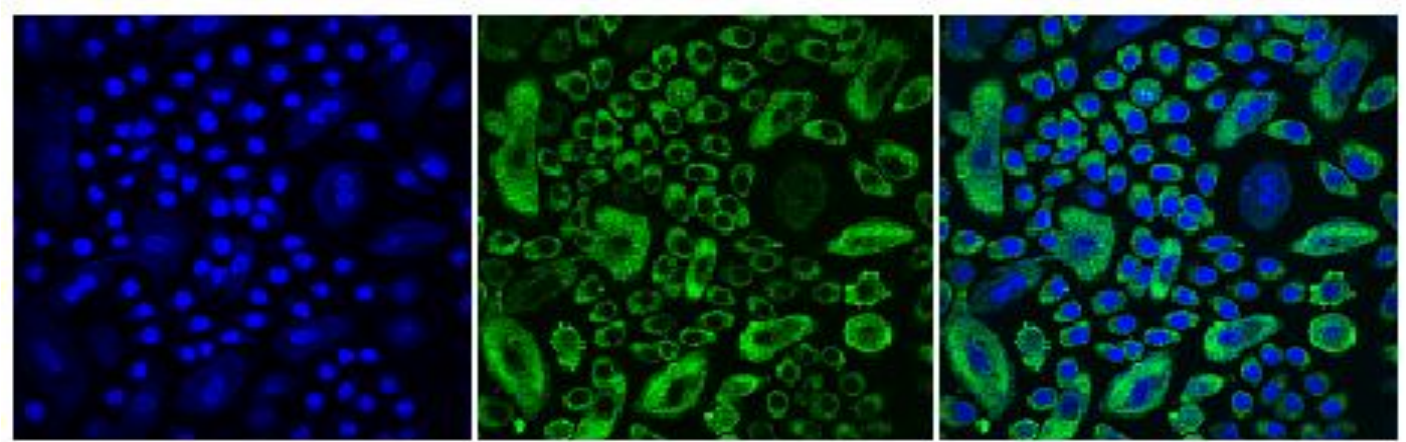

$\mathrm{UV}(+) \mathrm{SM}(+)$
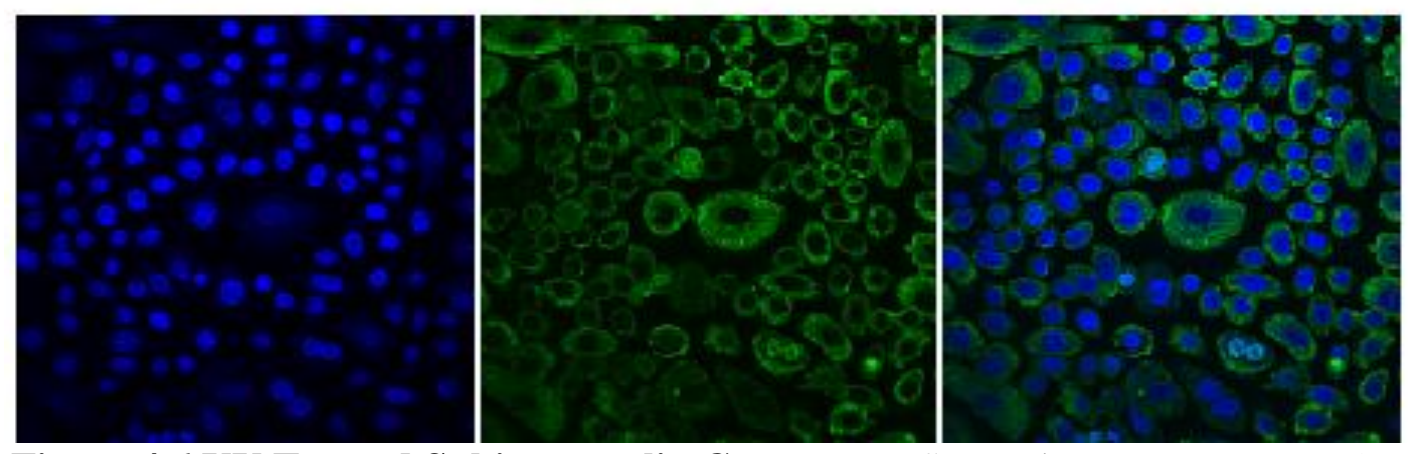

Figure 4.6 UV Treated Sphingomyelin Groups. No SM and no UV treatment (top row), No SM and UV treatment ( $2^{\text {nd }}$ row $), 0.1 \%$ Sphingomyelin and no UV treatment $\left(3^{\text {rd }}\right.$ row), and $0.1 \%$ Sphingomyelin and UV treatment (last row). 


\subsubsection{Raw Data}

The ratio of KRTs expressing p25 were manually counted using imageJ and the IntenseCount program and is shown in table 4.1 below. The highest expression of p53 positive KRTs were seen with the SM (-) UV (+) group, followed by the SM (+) UV (+), SM (+) UV (-) and SM (-) UV (-) groups. The difference between the both UV groups were significantly more than the difference between the no UV groups.

Table 4.2 The ratio of p53 positive cells being expressed in each treatment group

\begin{tabular}{|c|c|c|}
\hline $\begin{array}{c}\text { Treatment } \\
\text { Group }\end{array}$ & $\begin{array}{c}\text { Ratio of P53 Positive } \\
\text { KRTs }\end{array}$ & $\begin{array}{c}\text { Standard } \\
\text { Error }\end{array}$ \\
\hline SM (-) UV (-) & 0.047399015 & 0.015933562 \\
\hline SM (+) UV (-) & 0.034474101 & 0.00829868 \\
\hline SM (+) UV (+) & 0.057557255 & 0.006931191 \\
\hline SM (-) UV (+) & 0.082643619 & 0.010363842 \\
\hline
\end{tabular}

\subsubsection{Interpretations}

The ratio of cells expressing nuclear p53 for each group is shown in Figure 4.7. Similar to the trends found with p21, the SM (-) UV (+) treatment group was found to have the highest ratio of cells expressing nuclear p53, followed by SM (+) UV (+), SM () UV (-) and SM (+) UV (-). The data showed a significant difference in the ratio of p53 expression between both groups at the UV dosage level and both groups without UV exposure. This also supports the initial premise that p53 is an appropriate DNA damage biomarker to observe UV induced DNA damage, which is expected due to p53 being upstream of $\mathrm{p} 21$. No difference between the ratios of cells expressing nuclear $\mathrm{p} 53$ was observed between either groups at the no UV dosage level. This does not provide any evidence of SM having any adverse effects on KRTs health. There was a difference between the UV (-) SM (-) and the UV (+) SM (-) groups. This indicates that UV 
radiation did induce DNA damage and that p53 was expressed in the nucleus in response to this DNA damage. There was a significant difference between the SM (-) UV (+) and SM (+) UV (+) groups nuclear p53 expression. This decrease in p53 expression provides evidence of SM providing protection against UV induced DNA damage, which could have applications in preventing the formation of NMSC.

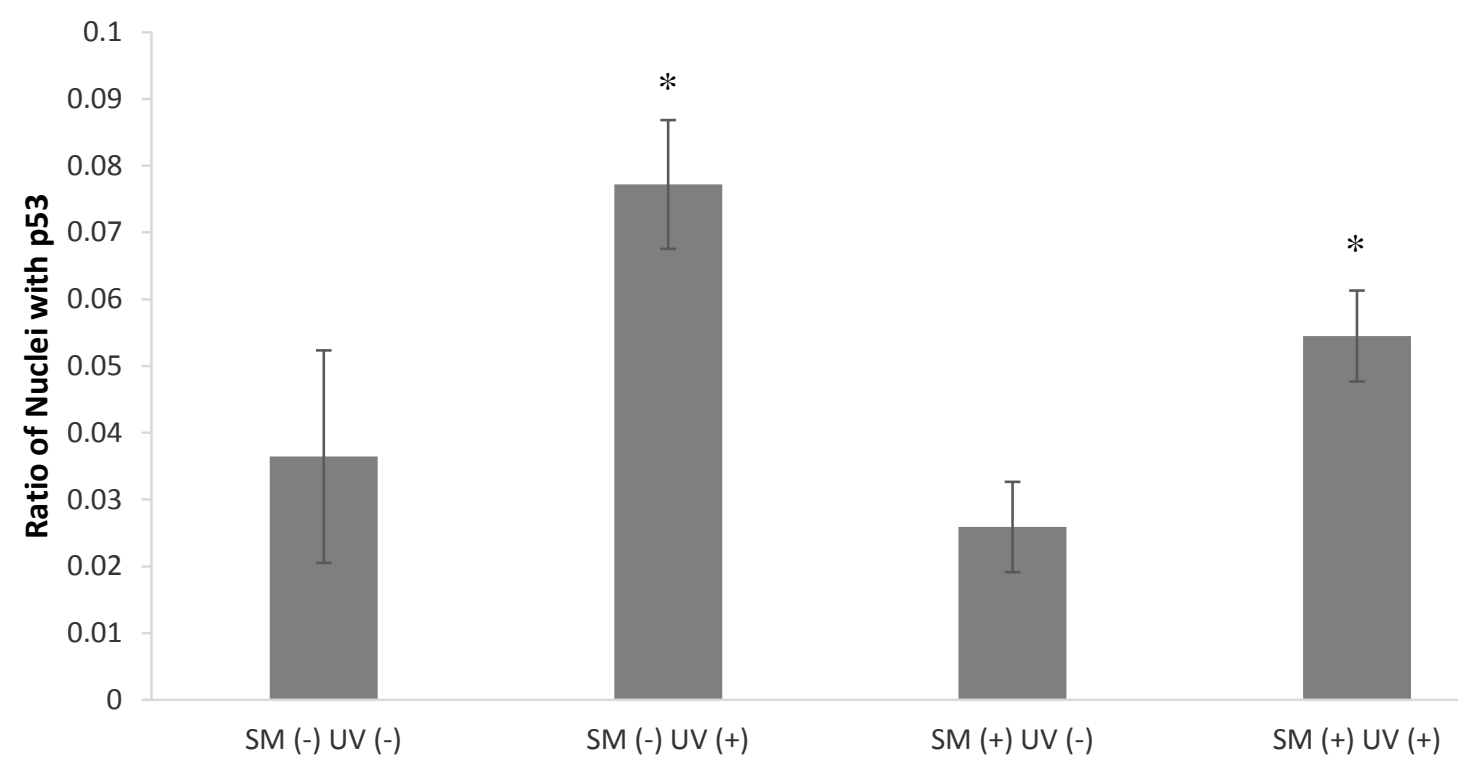

Figure 4.7 UV Treated Sphingomyelin Results. The ratio of cells expressing nuclear p53 compared to the total number of cells in each group is plotted above. $\left({ }^{*}\right) \mathrm{p}<0.05$; significant difference in ratio of cells expressing nuclear $\mathrm{p} 53$.

\subsection{Dual Staining Results}

The results for dual stain show similar trends to both p21 and p53. Representative images taken by the confocal microscope of the four treatment groups are shown in Figure 4.8. The hoechst stain is blue and indicates the location of the nucleus. The Alexa Fluor 488 is green and binds p53. The Alexa Fluor 647 is red and binds p21. As with the data for $\mathrm{p} 21$ and $\mathrm{p} 53$ above, bright green or red signal in the nuclear region indicates if the skin cells have taken UV damage. The SM (-) UV (+) group appeared to have the 
highest ratio of nuclear p53 and p21, followed by significantly lower expression in the remaining groups. It was also observed that p53 was expressed primarily in the cytoplasm in the UV (-) SM (-) group, but had much higher nuclear localization in UV (+) SM (-) group. Only a few wells from each treatment group had images appropriate for quantification, which made the number of samples too small for analysis. Further optimization of the protocol should allow for more images to be obtained to confirm these trends for dual staining. 


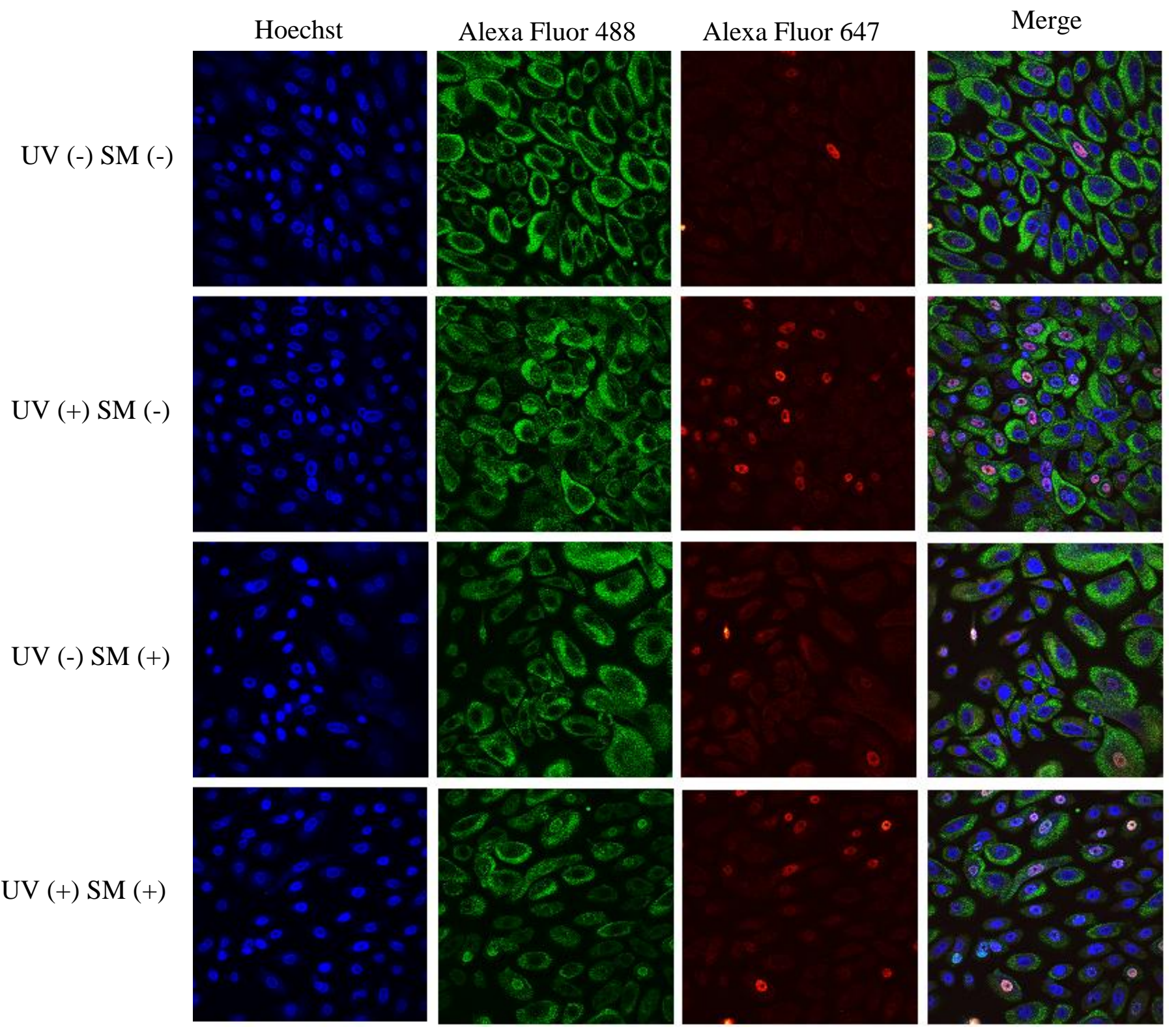

Figure 4.8 UV Treated Sphingomyelin Groups. No SM and no UV treatment (top row), No SM and UV treatment ( $2^{\text {nd }}$ row), $0.1 \%$ Sphingomyelin and no UV treatment ( $3^{\text {rd }}$ row), and $0.1 \%$ Sphingomyelin and UV treatment (last row). 


\section{Chapter 5: Discussion}

\subsection{Overview}

Identifying safer treatment alternatives to sunscreen has the potential to reduce the number of patients diagnosed with skin cancer without the adverse side effects of sunscreen. In particular, milk SM has been proposed to help prevent DNA damage associated with UV exposure. This study compared the expression of p21 and p53, two genes up-regulated by DNA damage, to assess if SM protects KRTs from UV induced DNA damage. A monolayer of KRTs were cultured into eight well plates and were treated with SM 24 hours prior to being exposed to $40 \mathrm{~mJ} / \mathrm{cm}^{2}$ of UVB radiation. Cells were then stained, imaged and analyzed and the ratio of cells expressing nuclear p21 and p53 was significantly decreased in the SM (+) UV (+) group compared to the SM (-) UV

(+) group. This decrease in both DNA damage biomarkers provides evidence to support that SM protects KRTs from UV exposure. In addition, a significant increase in the ratio of nuclear p21 and p53 expression was observed in the SM (-) UV (+) group when compared to the control, which supports the use of both of these markers as an indicator of DNA damage. Furthermore, no significant increase in either p21 or p53 intensities were found in the SM (+) UV (+) group compared to the SM (-) UV (-) group. This in combination with preliminary work with apoptotic and proliferative stains suggest that SM has no detrimental effect on cellular proliferation or apoptosis, which also supports SM as a safe treatment against DNA damage. These results suggest that SM is a safe treatment that can provide some protection against UV exposure, but could be insufficient to prevent all UV associated DNA damage. The hypothesis of the study was supported by the data. 


\subsection{Statistical Analysis Assumptions}

The one way ANOVA test was considered for the analysis of these experiments, but not all of the assumptions required to use one way ANOVA were met. The three assumptions needed include 1) samples are independent, 2) responses for a given group are normally distributed and 3) variances of populations between groups are equal. The first criteria was addressed by separating groups between different plates and taking random images in each well. The normalized responses are shown in the plots below (see Figure 5.1 and 5.2). Both $\mathrm{p} 21$ or $\mathrm{p} 53$ appears to follow normalized distributions within the confines of the $95 \%$ confidence interval, with p53 having a slightly more normalized response due to p53 more closely following the $95 \%$ confidence interval. The last criteria is that the samples have equal variances. The variances between groups do not appear to be equal between every group due to the control group having very large variances compared to the other treatment groups. As a consequence, the plots of residual frequency also do not appear to follow a normal distribution for either $\mathrm{p} 21$ or $\mathrm{p} 53$. The lack of equal variances might question the use of one way ANOVA and would also invalidate the post hoc Tukey's test. Since the control group's large variance is responsible for invalidating the assumptions underlying ANOVA and Tukey's test, both of the groups are assessed with t-tests to determine if sphingomyelin provides any photoprotective effects against UV damage. 

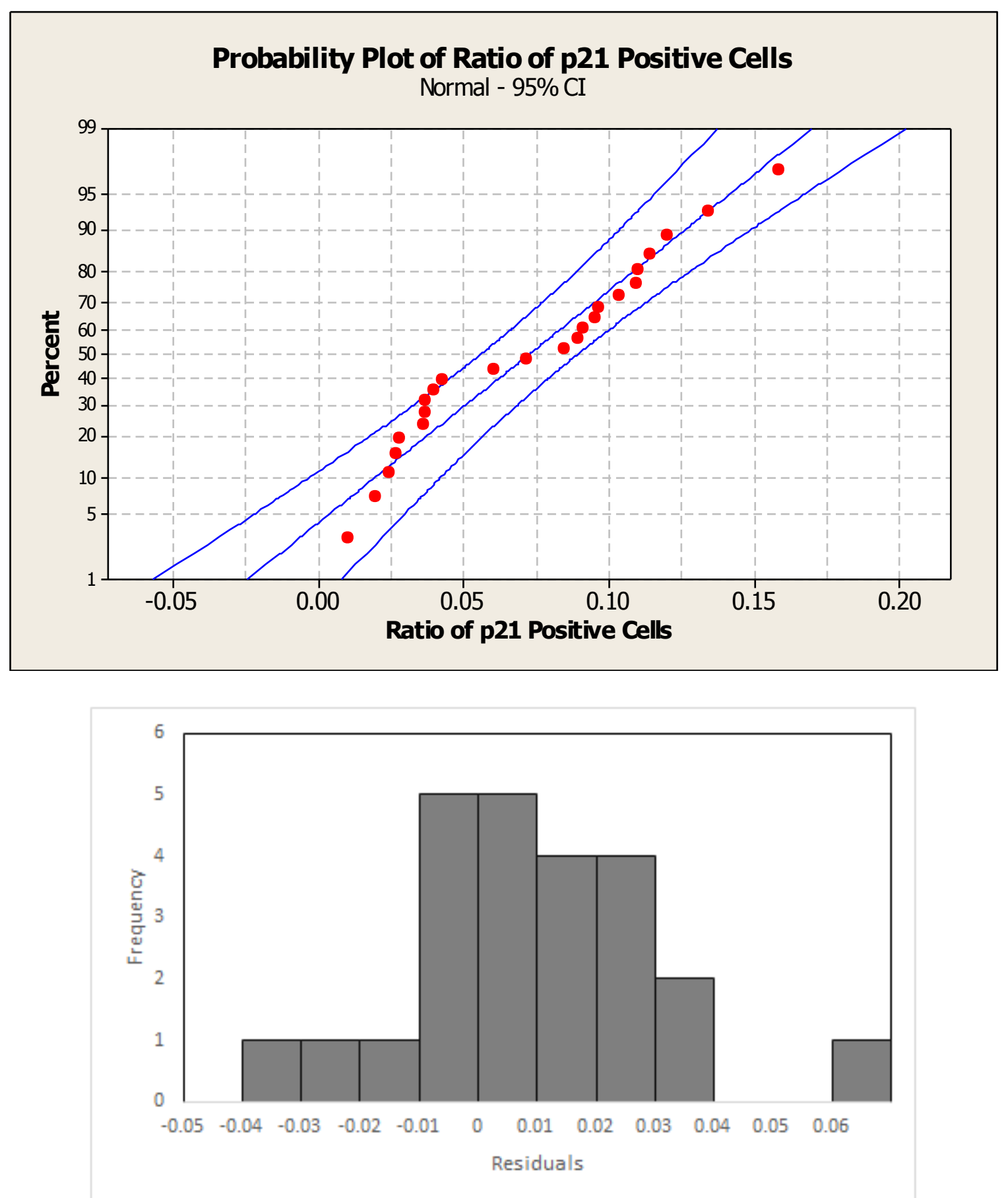

Figure 5.1 Residuals of p21 positive cells. A) Probability plot of p21 responses. B) Histogram of residuals of all treatment groups. 

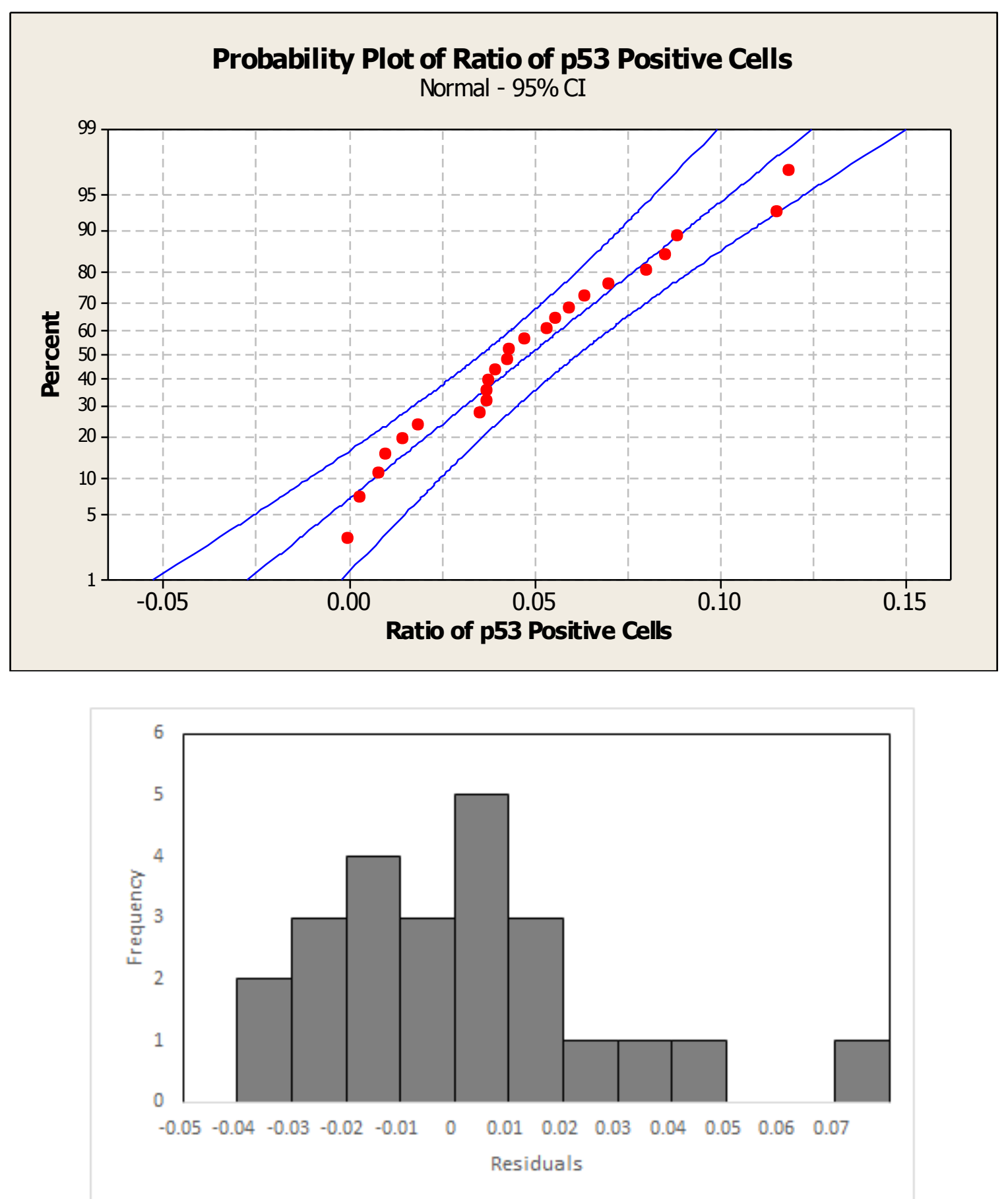

Figure 5.2 Residuals of p53 positive cells. A) Probability plot of p53 responses. B) Histogram of residuals of all treatment groups. 


\subsection{Observation of p21 and p53 as Biomarkers for DNA Damage}

DNA damage biomarkers p21 and p53 were ideal markers for analyzing DNA damage due to their response following UV induced DNA damage. Nuclear expression of p53 occurs nearly immediately following UV induced DNA damage and has been identified as a protein involved in gene transcription, DNA synthesis and repair [48]. Many cancers have been observed to have mutated or inhibited p53 expression, suggesting that p53 plays an important role in ensuring correct DNA synthesis and preventing the formation of cancer. In addition, increased expression of p53 has been linked to $\mathrm{G}_{2}$-phase arrest preventing the proliferation of potentially cancerous cells following DNA damage, further supporting the use of p53 as an indicator of DNA damage $[9,10,11]$. The nuclear expression of $\mathrm{p} 21$ is activated downstream of p53 indicative of DNA damage leading to inhibition of the G1 cyclins and kinases, but can also be expressed by other pathways (i.e transforming growth factor beta) [12]. The expression of both DNA biomarkers p21 and p53 should follow a similar expression if DNA damage is triggering the activation of these proteins and the expression of both markers should increase in the presence of DNA damaging radiation. The results found during the course of this experiment supports both of these suppositions, with both p21 and p53 following similar trends and UV exposure leading to an increase in expression for both markers.

\subsection{Theories on SM Mechanism for UV Protection}

Previous research in the lab suggested that exogenously added SM protects against UV induced DNA damage in KRTs potentially through the reduction of ROS formation within the cells [7]. This hypothesis would support SM treatment against the formation of 
NMSC by minimizing DNA damage present following UV exposure. SM is believed to be passively incorporated into the outer leaflet of the plasma membrane, where SM can interact with sphingomyelinases and provide integrity of the membrane [33]. SM was also believed to play a role in degrading lipid rafts found within the plasma membrane [33]. GM1 Ganglioside and cholesterol-rich microdomains (i.e lipid rafts) have been shown to generate damaging radical oxygen species following UVA irradiation [33]. The formation of radical oxygen species has been found to cause DNA damage and potentially lead to the progression of cancer. If SM does have the ability to degrade these lipid rafts before the KRTs are exposed to UV radiation, then the formation of radical oxygen species would subsequently be reduced following UV exposure. This could support SM as an anti-cancer therapy by inhibiting the production of these radical oxygen species which should lead to less DNA damage following UV radiation [34].

Limitations with this theory include the role UVA has on NMSC development and the consequences of dissolving lipid rafts. As previously stated, UVB is responsible for over $80 \%$ of NMSC cases and is typically not associated with radical oxygen species formation [34]. Although UVA radiation is primarily responsible for the remaining $20 \%$ of NMSC cases and is known for developing radical oxygen species in UV exposed cells, a treatment targeting UVA exposure would have much more limited application than a treatment targeting UVB exposure. In addition, the UV lamp used in these experiments was within the UVB range which questions why a significant decrease in both p21 and p53 were observed if SM decreases radical oxygen species formation primarily associated with UVA. Lipid rafts also are involved in many key physiological processes, including regulating chemical activity of cholesterol in membranes and participate in the 
processes of signal transduction [33]. Depletion of these lipid rafts have been found to inhibit cell signaling pathways, which could have a number of undesirable side effects associated with this treatment if SM does indeed degrade lipid rafts. The limited protection and potential adverse effects imparted by dissolving lipid rafts and preventing radical oxygen species has prompted interest in determining other theories explain SM observed UV protective properties.

Another theory on how SM might potentially protect against UV induced NMSC is that SM leads to an increase of ceramide, which is proapoptotic factor following UV induced cellular damage. SM has been found to increase sphingomyelinase activity, which leads to the formation of additional ceramide production within KRTs [49]. Ceramide has been shown to be recruited to lipid rafts following cell stress and accelerate apoptosis (see Figure 5.3), known as ceramide mediated tumor suppression [49]. Increasing the sensitivity of the KRTs to apoptotic signaling and accelerating the apoptosis process could help ensure that potentially carcinogenic cells undergo apoptosis instead of potentially forming NMSC. Apoptosis rates of KRTs following UVB radiation is well documented, with apoptosis initially present eight hours following UV radiation, peaking around 24-48 hours past UV exposure and disappears 60-72 hours later [50]. If the increase of SM and, consequently, ceramide does indeed accelerate apoptosis of severely damaged KRTs, then SM treated KRTs could have had more cells that have already undergone apoptosis prior to the 24 hour time point, leading to the reduced DNA damage biomarker expression observed here. This could suggest that SM has anti-cancer effects by helping ensure potentially cancerous cells undergo apoptosis instead of 
forming carcinomas and faster removal of these damaged KRTs could also help accelerate the repair process.

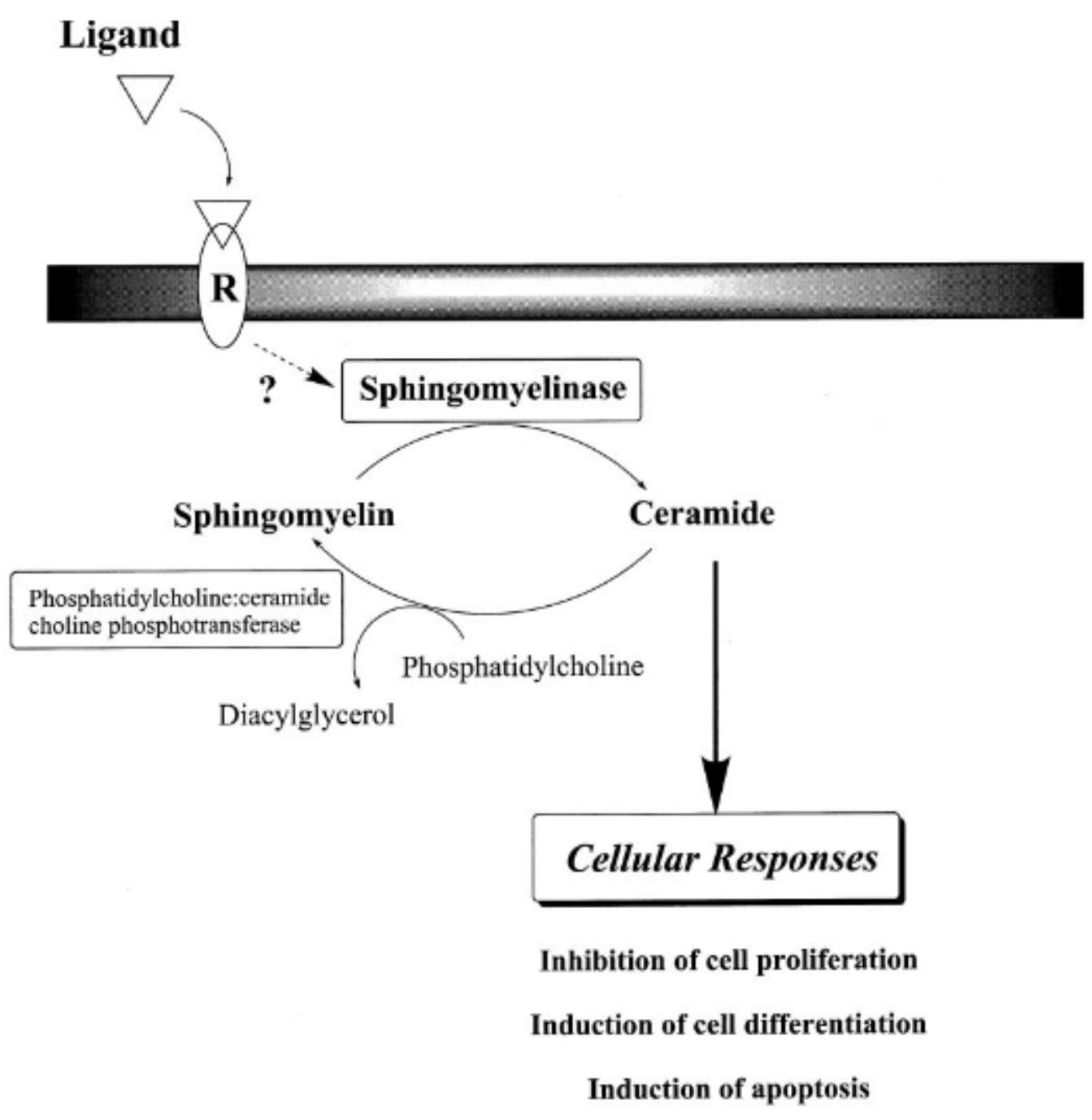

Figure 5.3 Role of sphingomyelin and ceramide in apoptosis [49].

\subsection{Limitations and Future Work}

The role of SM in preventing UV induced DNA damage or NMSC is still relatively unknown. It is quite possible that the effect of SM is a combination of reinforcing the plasma membrane, reducing radical oxygen species and accelerating apoptosis of potentially carcinogenic KRTs. Limitations with this study include having 
obtained no evidence to support a mechanism on how SM provides photoprotective properties to KRTs. Additional work with radical oxygen species detection, staining for ceramide and the addition of quantum dots to the SM phospholipid could illuminate the effect SM has within the cells and could allow for determination of the processes behind SM capacity to protect against UV induced DNA damage. Additional limitations with this study include not conducting extensive proliferation or apoptotic staining to ensure safe use of SM. Although preliminary tests have not observed any adverse effects with application of SM, any future therapeutic application of SM will require extensive tests to evaluate the safety of exogenous SM. Last, these experiments are only observing DNA damage biomarkers on a simple monolayer of KRTs. Future work should include analyzing UV induced DNA damage on skin tissue constructs to verify trends found in this study. Further work could also involve testing orally administered SM in an animal model to determine if SM application actually reduces precursor legions and tumor formation following prolonged UV exposure.

\subsection{Conclusions}

Bovine milk sphingomyelin was found to lead to a decrease in DNA damage biomarkers p21 and p53 following UV irradiation in human KRTs, which is indicative of preventing UV induced DNA damage. Both p21 and p53 markers showed a significant decrease in expression between the SM (+) UV (+) and SM (-) UV (+) groups providing evidence of SM imparting photoprotective effects to SM. The no UV groups had no significant difference in p21 and p53 expression, which provides no evidence of SM having adverse effects on the KRTs. The mechanism of how SM provides UV protection is still unknown. Different mechanisms, including preventing radical oxygen species, 
providing structural support and leading to the increased production of the ceramide mediated tumor suppression, have been proposed to support SM as a potential anti-cancer treatment. However, additional studies will have to be conducted to determine the accuracy of these proposed theories. In addition, more work will have to be conducted to ensure that exogenous SM is safe and effective. These tests could include proliferation and apoptotic stains on monolayers of KRTs, DNA damage biomarker expression within skin tissue constructs and animal models to determine effectiveness. This work found that SM treated KRTs reduced the expression of both p21 and p53 compared to KRTs without SM in the presence of UV, which could potentially support further research into SM as a treatment to safely prevent the onset of NMSC. 


\section{BIBLIOGRAPHY}

1. "Skin Cancer." Centers for Disease Control and Prevention. Centers for Disease Control and Prevention, 13 Jan. 2015. Web. 02 Feb. 2015.

2. Sinha, Rajeshwar P., and Donat-P. Häder. "UV-induced DNA Damage and Repair: A Review." Photochemical \& Photobiological Sciences 1.4 (2002): 22536.

3. "What Does the Sun Actually Do to Your Skin? Part 2." Thatscienceguy. N.p., 06 Feb. 2011. Web. 02 Feb. 2015.

4. Rass, Knuth, and Jorg Reichrath. "UV Damage and DNA Repair in Malignant Melanoma and Nonmelanoma Skin Cancer." Advances in Experimental Medicine and Biology (2008) 624: 162-178.

5. Goode, Ellen L., Cornelia M. Ulrich, and John D. Potter. "Polymorphisms in DNA Repair Genes and Associations with Cancer Risk." Cancer Epidemiology, Biomarkers \& Prevention 1513th ser. 11 (2002)

6. Skin Cancer Facts. Skin Cancer Facts. Skin Cancer Foundation, n.d. Web. 18 Oct. 2014.

7. De Guzman, Kathleen Y. Protective effects of sphingomyelin against UV photodamage in human keratinocytes. Cal Poly Digital Commons (2013): 1-124. Digital Commons.

8. Smijs, Threes G., and Stanislav Pavel. Titanium Dioxide and Zinc Oxide Nanoparticles in Sunscreens: Focus on Their Safety and Effectiveness. Dove Press Journal, 12 Oct. 2011.

9. Namba H, Hara T, Tukazaki T, Migita K, Ishikawa N, Ito K, Nagataki S, Yamashita S. Radiation-induced G1 arrest is selectively mediated by the p53WAF1/CIP1 pathway in human thyroid cells. Cancer Research (1999) 55 (10): 2075-2080.

10. Rigberg DA, Blinman TA, Kim FS, Cole MA, McFadden DW. Antisense blockade of p21/WAF1 decreases radiation-induced G2 arrest in esophageal squamous cell carcinoma. J Sugical Research. (1999) 81(1): 6-10

11. Azzam EI, de Toledo SM, Pykett MJ, Nagasawa H, Little JB. CDC2 is downregualated by ionizing radiation in a p53-dependent manner. Cell growth \& differentiation. (1997) 8 (11): 1161-1169. 
12. Datto, M. B., Y. Li, J. F. Panus, D. J. Howe, Y. Xiong, and X. F. Wang. "Transforming Growth Factor Beta Induces the Cyclin-dependent Kinase Inhibitor P21 through a P53-independent Mechanism." Proceedings of the National Academy of Sciences 92.12 (1995): 5545-549.

13. Gartel, Andrei L., and Angela L. Tyner. "The Role of the Cyclin-dependent Kinase Inhibitor P21 in Apoptosis." Molecular Cancer Therapeutics 1.639 (2002): n. pag. Print.

14. Rook, Arthur, and Tony Burns. "CHAPTER 3 Anatomy and Organization of Human Skin." Rook's Textbook of Dermatology. Chichester, West Sussex, UK: Wiley-Blackwell, 2010. N. pag. Print.

15. Madan, Vishal, John T. Lear, and Rolf-Markus Szeimies. "Non-melanoma Skin Cancer." The Lancet 375.9715 (2010): 673-85.

16. Diffey, Brian L. "Sources and Measurement of Ultraviolet Radiation." Methods 28.1 (2002): 4-13.

17. Gruijl, F.r. De. "Skin Cancer and Solar UV Radiation." European Journal of Cancer 35.14 (1999): 2003-009.

18. Nelson, David L., David L. Nelson, Albert L. Lehninger, and Michael M. Cox. Lehninger Principles of Biochemistry. New York: W.H. Freeman, 2008. Print.

19. O'donovan, Peter O., Conal M., Xiaohong Zhang, Beatriz Montaner, Yao-Zhong $\mathrm{Xu}$, Catherine A. Harwood, Jane M. McGregor, Susan L. Walker, Fumio Hanaoka, and Peter Karran. "Azathioprine and UVA Light Generate Mutagenic Oxidative DNA Damage." Science 309.5742 (2005): 1871-874.

20. Leiter, Ulrike, and Claus Garbe. "Epidemiology of Melanoma and Nonmelanoma Skin Cancer-The Role of Sunlight." Sunlight, Vitamin D and Skin Cancer Advances in Experimental Medicine and Biology (2008): 89-103.

21. Saraiya, Mona, Karen Glanz, Peter Briss, Cronelia White, and Debjani Das. "Preventing Skin Cancer." Centers for Disease Control and Prevention. Centers for Disease Control and Prevention, n.d. Web. 01 June 2015.

22. Duquia, Rodrigo Pereira, Ana Maria Baptista Menezes, Felipe Fossati Reichert, and Hiram Larangeira De Almeida. "Prevalence and Associated Factors with Sunscreen Use in Southern Brazil: A Population-based Study." Journal of the American Academy of Dermatology 57.1 (2007): 73-80.

23. Gasparro, Francis P., Mark Mitchnick, and J. Frank Nash. "A Review of Sunscreen Safety and Efficacy." Photochemistry and Photobiology Photchem. Photbio. 68.3 (1998): 243 
24. Kuman, Sujit, and Roop N. Gupta. "Safety and Regulatory Issues on Sunscreen Products in India." Archives of Applied Science Research 5.2 (2013): 145-53.

25. Collins, P., and J. Ferguson. "Photoallergic Contact Dermatitis to Oxybenzone." Br J Dermatol British Journal of Dermatology 131.1 (1994): 124-29.

26. Graves, E.1.f., A.d. Beaulieu, and J.k. Drackley. "Factors Affecting the Concentration of Sphingomyelin in Bovine Milk." Journal of Dairy Science 90.2 (2007): 706-15.

27. "Ceramides and Ceramide Metabolites in Cell Regulation: Evidence for Dietary Sphingomlipids as Inhibitors of Colon Carcingenesis." Nutrition 14.9 (1998): 717.

28. Russell, Ashley, Andrea Laubscher, Rafael Jimenez-Flores, and Lily H. Laiho. "Investigating the Protective Properties of Milk Phospholipids against Ultraviolet Light Exposure in a Skin Equivalent Model." Multiphoton Microscopy in the Biomedical Sciences X (2010)

29. Contarini, Giovanna, and Milena Povolo. "Phospholipids in Milk Fat: Composition, Biological and Technological Significance, and Analytical Strategies." IJMS International Journal of Molecular Sciences 14.2 (2013): 2808831.

30. Selzner, Markus, Alicja Bielawska, Michael A. Morse, Hannes A. Ruidiger, David Sindram, Yusuf A. Hannun, and Pierre-Alain Clavien. "Induction of Apoptotic Cell Death and Prevention of Tumor Growth by Ceramide Analogues in Metastatic Human Colon Cancer." Cancer Research 61 (2001): 1233.

31. Mcintosh, Thomas J., Sidney A. Simon, David Needham, and Ching Hsien Huang. "Structure and Cohesive Properties of Sphingomyelin/cholesterol Bilayers." Biochemistry 31.7 (1992): 2012-020.

32. Pillai, S., Manisha Mahajan, and Marieann Carlomusto. "Ceramide Potentiates, but Sphingomyelin Inhibits, Vitamin D-induced Keratinocyte Differentiation: Comparison between Keratinocytes and HL-60 Cells." Archives of Dermatological Research 291.5 (1999): 284-89.

33. Gniadecki, Robert, Nanna Christoffersen, and Hans Christian Wulf. "CholesterolRich Plasma Membrane Domains (Lipid Rafts) in Keratinocytes: Importance in the Baseline and UVA-Induced Generation of Reactive Oxygen Species." J Invest Dermatol Journal of Investigative Dermatology 118.4 (2002): 582-88.

34. Wiseman, Helen, and Barry Halliwell. "Damage to DNA by Reactive Oxygen and Nitrogen Species: Role in Inflammatory Disease and Progression to Cancer." Biochemical Journal 313 (1996): 17-29. 
35. Lingwood, D., and K. Simons. "Lipid Rafts As a Membrane-Organizing Principle." Science 327.5961 (2009): 46-50.

36. Waldman, Todd, Kenneth W. Kinzler, and Bert Vogelstein. "P21 Is Necessary for the P53-mediated G1 Arrest in Human Cancer Cells." Cancer Research 55 (1995): 5187-190.

37. Trahey, Meg, Robert J. Milley, Georgette E. Cole, Michael Innis, Hugh Paterson, Christopher Marshall, Alan Hall, and Frank McCormick. "Biochemical and Biological Properties of the Human N-ras P21 Protein." Molecular and Cellular Biology 7.1 (1987): 541-44.

38. Waga, Shou, Gregory J. Hannon, David Beach, and Bruce Stillman. "The P21 Inhibitor of Cyclin-dependent Kinases Controls DNA Replication by Interaction with PCNA." Nature 369.6481 (1994): 574-78.

39. Sancar, Aziz, Laura A. Lindsey-Boltz, Keziban Unsal-Kacmaz, and Stuart Linn. "MOLECULAR MECHANISMS OF MAMMALIAN DNA REPAIR AND THE DNA DAMAGE CHECKPOINTS." Biochemistry 73 (2004): 39-85.

40. Elledge, S. J. "Cell Cycle Checkpoints: Preventing an Identity Crisis." Science 274.5293 (1996): 1664-672.

41. Harper, J. Wade, Guy R. Adami, Nan Wei, Khandan Keyomarsi, and Stephen J. Elledge. "The P21 Cdk-interacting Protein Cip1 Is a Potent Inhibitor of G1 Cyclin-dependent Kinases." Cell 75.4 (1993): 805-16.

42. Sherr, C. J., and J. M. Roberts. "CDK Inhibitors: Positive and Negative Regulators of G1-phase Progression." Genes \& Development 13.12 (1999): 1501512.

43. Moldovan, George-Lucian, Boris Pfander, and Stefan Jentsch. "PCNA, the Maestro of the Replication Fork." Cell 129.4 (2007): 665-79.

44. Funk, Walter D., Daniel T. Pak, Richard H. Karas, Woodring E. Wright, and Jerry W. Shay. "A Transcriptionally Active DNA-Binding Site for Human P53 Protein Complexes." Molecular and Cellular Biology 12.6 (1992): 2866-871.

45. Cho, Y, Gorina S, Jeffrey P. D, and Pavletich N. P. "Crystal Structure of a P53 Tumor Suppressor-DNA Complex: Understanding Tumorigenic Mutations." Science 265.5170 (n.d.): 346-55.

46. Bunz, F., A. Dutriaux, C. Lengauer, T. Waldman, S. Zhou, P. Brown, J. M. Sedivy, K. W. Kinzler, and B. Vogelstein. "Requirement for P53 and P21 to Sustain G2 Arrest After DNA Damage." Science 282.5393 (1998): 1497-501. 
47. Snellman, E., C. T. Jansén, K. Leszczynski, R. Visuri, T. Milan, and K. Jokela. "ULTRAVIOLET ERYTHEMA SENSITIVITY IN ANAMNESTIC (I-IV) and PHOTOTESTED (1-4) CAUCASIAN SKIN PHOTOTYPES: THE NEED FOR A NEW CLASSIFICATION SYSTEM." Photochemistry and Photobiology Photochem Photobiol 62.4 (1995): 769-72.

48. Greenblatt, M. S., W. P. Bennett, M. Hollstein, and C. C. Harris. "Mutations in the P53 Tumor Suppressor Gene: Clues to Cancer Etiology and Molecular Pathogenesist." Cancer Research 54 (1994): 4855-878.

49. Geilen, C. G., Thomas Wieder, and Constantin E. Orfanos. "Ceramide Signalling: Regulatory Role in Cell Proliferation, Differentiation and Apoptosis in Human Epidermis." Archives of Dermatological Research 289.10 (1997): 559-66.

50. Kulms, D., and T. Schwarz. "Molecular Mechanisms of UV-induced Apoptosis." Photodermatology, Photoimmunology and Photomedicine Photoderm Photoimm Photomed 16.5 (2000): 195-201. 